Research Article

\title{
Electromagnetic Force and Mechanical Response of Turbo-Generator End Winding under Electromechanical Faults
}

\author{
Hong-Chun Jiang (D), Yu-Ling He, Gui-Ji Tang, and Xing-Hua Yuan \\ Department of Mechanical Engineering, The Hebei Key Laboratory of Electric Machinery and Failure Prevention, \\ North China Electric Power University, Baoding 071003, China
}

Correspondence should be addressed to Hong-Chun Jiang; spring.jh@163.com

Received 17 August 2021; Revised 11 November 2021; Accepted 1 December 2021; Published 23 December 2021

Academic Editor: Bartlomiej Blachowski

Copyright (c) 2021 Hong-Chun Jiang et al. This is an open access article distributed under the Creative Commons Attribution License, which permits unrestricted use, distribution, and reproduction in any medium, provided the original work is properly cited.

\begin{abstract}
This paper comparatively studies the electromagnetic force and mechanical response of the end winding before and after 3 kinds of typical electromechanical faults in turbo-generator. The analytical expression of electromagnetic force of end winding is derived under the composite fault of static eccentricity and rotor interturn short circuit. Meanwhile, the three-dimensional transient finite element simulation is carried on, and the frequency composition and amplitude variation characteristics of the radial, axial, and tangential electromagnetic force are analyzed for the end windings under static eccentricity, rotor interturn short circuit, and composite fault. Therefore, it provides a reference for the vibration wear detection and electromagnetic force control of the end winding. Moreover, the maximum stress and deformation of different positions on the end involute are obtained. And the threedirectional vibration acceleration characteristics of the end winding are further analyzed. Finally, the distribution law of winding fatigue failure and vibration wear is acquired, which lays a foundation for the reverse suppression of end winding fatigue failure and insulation wear.
\end{abstract}

\section{Introduction}

In the actual operation, generator is not only in normal state, but also in abnormal states probably. The static air gap eccentricity is a kind of mechanical fault which is a certain offset between rotor and stator axis. Due to the manufacturing and installation errors, almost all generators have certain of static eccentricity. Especially for large turbogenerators, the static eccentricity is inevitable because the supporting parts of the shaft are sliding bearings. At the meantime, it is very easy for rotor windings to appear short circuit phenomenon between turns, because of copper wire structure defects, the interturn insulation damage, fatigue damage and insulation aging under mechanical stress. And it is an electrical fault with high frequency in the actual working process of generator. These two kinds of mechanical and electrical faults will not seriously affect the operation of the generator in the early stage and the generator can work with them, but they will cause abnormal distribution of air gap magnetic field. The electromagnetic force of the end winding will be further affected. And alternating stress and vibration of some windings will increase, which will result in fatigue damage and wearing. When they develop to a certain extent, coil short circuit will be caused $[1,2]$. However, the fault caused by the end damage of generator stator winding is not easy to monitor, and it will appear suddenly in general. Once the end winding fault occurs, it needs a lot of manpower and time to repair. Therefore, such failure will cause huge maintenance and downtime loss, and effective measures should be taken to prevent it. The traditional method is improving the rigidity and strength of the end winding support or increasing the number of binding parts. But it will waste materials, bring the installation complexity, and lead to the increase of generator processing cost. By calculating the electromagnetic force and mechanical response of the generator end winding, the maximum stress and vibration characteristics can be obtained under various operating conditions. It can be used for the end winding structure 
optimization, the processing technology improvement, and the key maintenance position location, so as to reduce the manufacturing and maintenance cost of the generator to a certain extent.

When slight winding interturn short circuit and air gap eccentricity appear, the generator can still run for a long time, so this kind of electromechanical fault is often ignored. However, with the aggravation of short circuit and eccentricity, the electromechanical characteristics of the generator will have considerable changes. $\mathrm{Wu}$ and $\mathrm{Li}$ found a new frequency component of the air gap magneto motive force when the interturn short circuit fault occurs [3]. Based on this principle, Sun et al. invented a new type of detection coil to identify this fault. When the rotor interturn short circuit (RISC) occurs, the detection coil terminal voltage causes even or fractional harmonics, while when the stator interturn short circuit (SISC) occurs, the terminal voltage only contains odd harmonics [4]. In addition, the difference between the actual electromagnetic power and the calculated virtual work of the generator will increase with the occurrence of interturn short circuit [5]. In order to avoid RISC, the method of BP neural network and online monitoring was proposed to identify this fault $[6,7]$. Furthermore, a compound diagnosis method based on stator/rotor vibration characteristics was proposed to determine the RISC position and degree $[8,9]$. On the other hand, Iamamura et al. found that when the rotor is eccentric, the magnetic field shifts with the change of the eccentric angle [10-12]. Moreover, radial eccentricity will increase the harmonic components and amplitude of electromagnetic torque, while the impaction of axial eccentricity is on the opposite $[13,14]$. Ehya et al. summarized the eccentricity detection methods according to harmonic components of voltage and current, efficiency, temperature, and electromagnetic torque fluctuation [15]. In the aspect of composite fault referring to air gap dynamic eccentricity, static eccentricity, RISC, and SISC, He Yuling et al. analyzed the potential difference of internal circulation in parallel branches, electromagnetic torque characteristics, and unbalanced electromagnetic force $[16,17]$. At the same time, scholars have also studied the excitation current, flux density, stator current, and voltage when composite electromechanical fault occurs [18-21].

In summary, most of the literatures focus on the electromagnetic characteristics of generator and the vibration characteristics of iron core under air gap eccentricity and interturn short circuit faults, and there are few researches on the electromagnetic force and mechanical response characteristics of stator end winding under this kind of faults. He et al. found that the even harmonics increment of the winding electromagnetic force becomes larger with the increase of the SISC degree [22]. Meanwhile, the variation of the stator winding electromagnetic force and the static maximum mechanical response of the whole windings under RISC are analyzed [23]. It is pointed out that RISC will increase the amplitude of the odd harmonics of the stator winding electromagnetic force. Moreover, the electromagnetic force and transient mechanical response characteristics of stator end winding before and after air gap static eccentricity were studied, and it was found that the coil closest to the minimum air gap is the most dangerous [24].

As an important complementary, this paper mainly studies the electromagnetic force excitation behaviours and mechanical response of generator stator end winding under the composite electromechanical fault of air gap static eccentricity and RISC and comparatively analyses the characteristics in normal, eccentricity, RISC, and composite fault. The stress result can provide a basis for targeted reverse design, and the deformation distribution is a guidance of wear failure prevention and daily examination. Moreover, the force and vibration characteristics have certain significance in fault diagnosis.

The remainder of this paper is constructed as follows. The analytical formulas of the electromagnetic force on the end windings under composite fault are derived in Section 2. Then, the finite element analysis of the electromagnetic force and mechanical response are carried out in Section 3, while the experimental study is conducted in Section 4. Finally, the differences of the behaviours in four states are summarized in Section 5 and the main conclusions are drawn up in Section 6.

\section{Theoretic Analysis}

2.1. Air Gap Magnetic Flux Density (MFD). The air gap MFD can be obtained by the multiplication of the unit permeance and the magnetic motive force (MMF). The static air gap eccentricity will change the permeance distribution, and the RISC will have an influence on the MMF. Therefore, the air gap MFD will change under these electromechanical faults.

The unit permeance is inversely proportional to the radial length of air gap. As the static eccentricity will cause the change of the radial air gap length, as shown in Figure 1, the permeance will be further varied. The permeance in unit area can be expressed as [14]

$$
\begin{aligned}
\Lambda(\alpha) & =\frac{\mu_{0}}{\delta(\alpha)} \\
& =\frac{\mu_{0}}{\delta_{0}[1-\varsigma \cos (\alpha-\lambda)]} \approx \Lambda_{0}[1+\varsigma \cos (\alpha-\lambda)],
\end{aligned}
$$

where $\alpha$ is the circumferential position, $\delta(\alpha)$ represents the air gap length of different position, $\Lambda_{0}$ refers to the normal permeance $\left(\Lambda_{0}=\mu_{0} / \delta_{0}, \mu_{0}\right.$ and $\delta_{0}$ are the vacuum permeability and normal air gap length, respectively), $\zeta$ is the relative eccentricity ratio $\left(\zeta=e / \delta_{0}, e\right.$ is the absolute eccentricity value), and $\lambda$ is the eccentricity angle as shown in Figure 1.

As indicated in equation (1), it is evident that the static eccentricity will make the air gap permeance no longer uniform along the circumferential direction and the permeance near the minimum air gap (within $\pm 90^{\circ}$ from the eccentricity direction) will increase, while the permeance near the maximum air gap will decrease.

On the other hand, the air gap MMF is the superposition of the stator and rotor winding MMF. According to [24], the normal stator and rotor winding MMF can be written as 


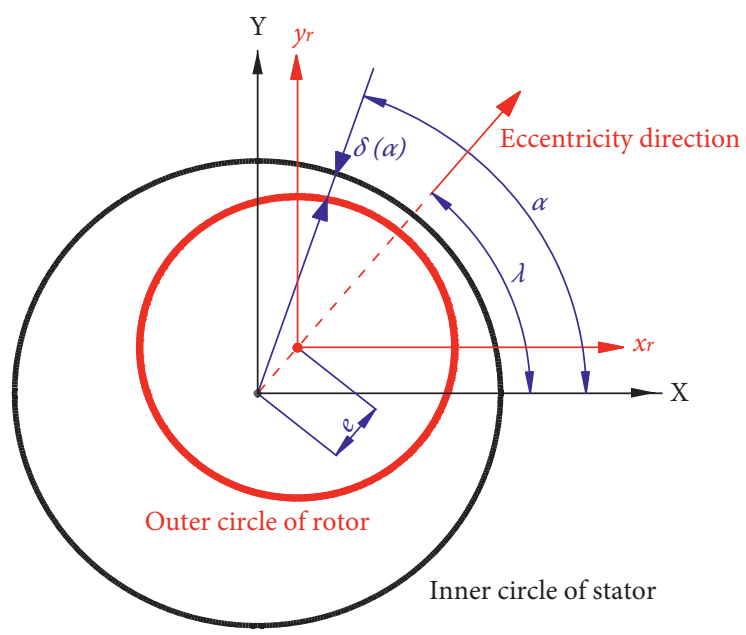

FIgure 1: Diagram of air gap static eccentricity.

$$
\left\{\begin{array}{l}
f_{r}(\alpha, t)=\sum_{n=1,3,5 \ldots} F_{r n} \cos n(\omega t-\alpha), \\
f_{s}(\alpha, t)=\sum_{n=1,3,5 \ldots} F_{s n} \cos [n(\omega t-\alpha)-\psi-0.5 \pi],
\end{array}\right.
$$

where $\psi$ is the internal power angle of generator, $\omega$ is the electrical frequency, and $F_{s n}$ and $F_{r n}$ are the $n$-th harmonics amplitude of stator and rotor winding MMF, respectively.

When the RISC happens, the reverse MMF will be brought by the shorted turn circuit. As shown in Figure 2(a), the shorted turn position is defined as $\beta^{\prime}, \beta^{\prime} \in(0 \sim \pi)$. According to the law of magnetic flux conservation, the distribution of reverse MMF is shown in Figure 2(b), and it can be expressed as [25]

$$
F_{d}(\alpha)= \begin{cases}-\frac{I_{f} n_{m}\left(\pi-\beta^{\prime}\right)}{\pi}, & -\beta^{\prime} \leq \alpha \leq \beta^{\prime}, \\ \frac{I_{f} n_{m} \beta^{\prime}}{\pi}, & \text { others }\end{cases}
$$

where $I_{f}$ is the current of shorted turn and $n_{m}$ is the number of the shorted turn.

Considering the rotor is rotating at the angle velocity of $\omega_{r}$ (for the turbo-generator with one pair of poles, $\omega=\omega_{r}$ ), the reverse MMF can be expanded by FFT as

$$
\left\{\begin{array}{l}
F_{d}(\alpha)=-\sum_{u=1}^{\infty} F_{d u} \cos u\left(\omega_{r} t-\alpha\right)=-\sum_{u=1}^{\infty} F_{d u} \cos u(\omega t-\alpha), \\
F_{d u}=\frac{2 I_{f} n_{m} \sin (u \beta \prime)}{u \pi},
\end{array}\right.
$$

where the absolution of $F_{d u}$ represents the amplitude of the $u$-th harmonic of reverse MMF.

Because the rotor MMF is the main part, the influence of the fault on the stator MMF can be neglected. Therefore, the air gap MMF after RISC can be written as

$$
\left\{\begin{array}{l}
f(\alpha, t)=\sum_{n=1,3,5 \ldots}\left[\left(F_{r n}-F_{d n}\right) \cos n(\omega t-\alpha)+F_{s n} \cos [n(\omega t-\alpha)-\psi-0.5 \pi]\right]-\sum_{u=2,4,6 \ldots} F_{d u} \cos u(\omega t-\alpha) \\
\quad=\sum_{n=1,3,5 \ldots} F_{c n} \cos n\left(\omega t-\alpha-\rho_{n}\right)-\sum_{u=2,4,6 \ldots} F_{d u} \cos k(\omega t-\alpha) \approx F_{c 1} \cos \left(\omega t-\alpha-\rho_{1}\right), \\
F_{c 1}=\sqrt{F_{s 1}^{2} \cos ^{2} \psi+\left(F_{r 1}-F_{d 1}-F_{s 1} \sin \psi\right)^{2}}, \\
\rho_{1}=\arctan \frac{F_{s 1} \cos \psi}{F_{r 1}-F_{d 1}-F_{s 1} \sin \psi},
\end{array},\right.
$$

where $F_{c n}$ is the amplitude of the $n$-th harmonic of summed MMF and $\rho_{n}$ is the angle between the summed MMF and rotor MMF vector.
As indicated in equation (5), RISC brings new components of even harmonics to the summed MMF. Because the shorted turn is relatively less, the amplitude of even 


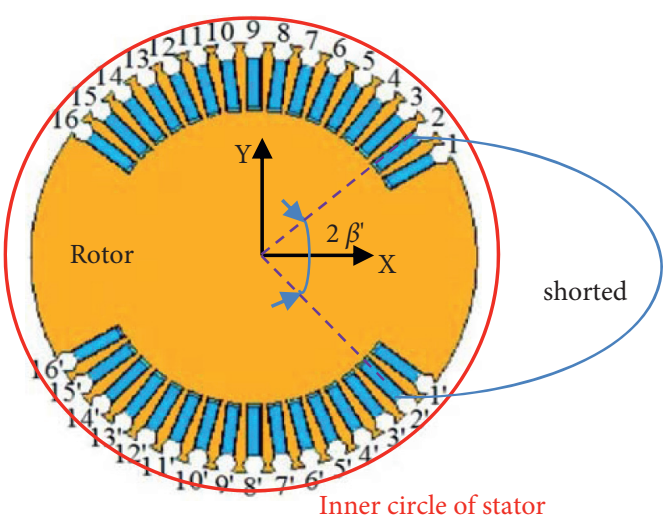

(a)

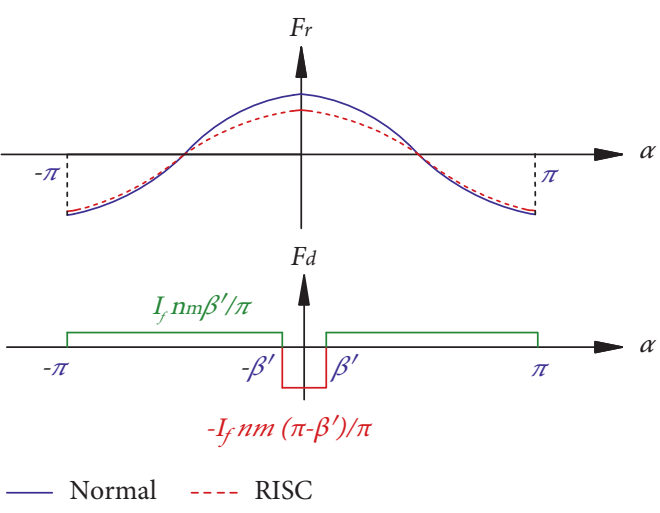

(b)

FIGURE 2: MMF of RISC. (a) Rotor windings and (b) inverse MMF (only 1st harmonic of the normal MMF is considered).

harmonics is very weak. Moreover, the amplitude of original odd harmonics varies and its trend depends on the sine value relating to shorted position and harmonic order, that is, $\sin \left(n \beta^{\prime}\right)$. For the fundamental harmonic, $\sin \left(\beta^{\prime}\right)>0$ is permanent owing to $\beta^{\prime} \in(0 \sim \pi)$, so $F_{d 1}>0$ is constant. Therefore, no matter where the shorted turn is, the fundamental harmonic amplitude of the summed MMF $F_{c 1}$ will decrease.

When the composite fault of RISC and eccentricity happens, the final air gap MFD can be obtained by multiplying the RISC MMF and eccentricity permeance.

$$
\begin{aligned}
B(\alpha, t)= & f(\alpha, t) \Lambda(\alpha) \\
= & \Lambda_{0}[1+\varsigma \cos (\alpha-\lambda)] \times\left[\sum_{n=1,3,5 \ldots}\left[\left(F_{r n}-F_{d n}\right) \cos n(\omega t-\alpha)+F_{s n} \cos [n(\omega t-\alpha)-\psi-0.5 \pi]\right]\right. \\
& \left.-\sum_{u=2,4,6 \ldots} F_{d u} \cos u(\omega t-\alpha)\right] \approx \Lambda_{0} F_{c 1}[1+\varsigma \cos (\alpha-\lambda)] \cos \left(\omega t-\alpha-\rho_{1}\right) .
\end{aligned}
$$

It is shown in equation (6) that the MFD contains the even harmonics besides odd harmonics when the RISC or composite fault happens. Moreover, under composite fault, the fundamental harmonic amplitude of the MFD near the min air gap is between the values under eccentricity and RISC, and it is less than the value under the two single faults near the max air gap.
2.2. Electromagnetic Force of End Winding. The main MFD can be got by the multiplication of rotor MMF and permeance.

$$
B_{r}(\alpha, t)=\Lambda_{0}[1+\varsigma \cos (\alpha-\lambda)]\left[\sum_{n=1,3,5 \ldots}\left(F_{r n}-F_{d n}\right) \cos n(\omega t-\alpha)-\sum_{u=2,4,6 \ldots} F_{d u} \cos u(\omega t-\alpha)\right] .
$$

According the electromagnetic induction rule, the stator current can be described as 


$$
\left\{\begin{array}{l}
I(t)=\sum_{n=1,3,5 \ldots} I_{n} \cos \frac{n(\omega t-\alpha)-\psi-\pi}{2}+\sum_{u=2,4,6 \ldots} I_{u} \cos \left[\frac{u(\omega t-\alpha)-\psi-\pi}{2}\right], \\
I_{n}=\frac{q}{|Z|} w_{s} k_{w n} \Lambda_{0} L v\left(F_{r n}-F_{d n}\right)[1+\varsigma \cos (\alpha-\lambda)], \\
I_{u}=\frac{q}{|Z|} w_{s} k_{w u} \Lambda_{0} L v F_{d u}[1+\varsigma \cos (\alpha-\lambda)],
\end{array}\right.
$$

where $I_{n}$ and $I_{u}$ are the $n$-th and $u$-th harmonic amplitude of stator current, respectively. $L$ is the effective axial length of the winding, $v$ is the velocity where the coil bar cuts the magnetic flux lines, $Z$ is the impedance of the winding, $q$ is the slot number per phase, $w_{s}$ is the turn number per coil, and $k_{w n}$ is the winding factor of the $n$-th harmonic (for details see [24]).

The line part of stator winding lies in the stator slot, and the end involute part hangs outside the slot, as shown in Figure 3. Since the MFD in the end zone is a leakage magnetic field, it is less than the line part. But the MFD harmonics components are the same for the two parts. Therefore, the end zone MFD is modified by adding the coefficient $f_{k}$. Here, the coefficient is related to the spatial position, work condition, and so on. It can be further obtained by large amounts of experiments and simulation.

According to the ampere force law, the electromagnetic force is the cross product of current and MFD. So the electromagnetic force at any point $K$ of the end winding under composite fault can be deduced as

$$
\begin{aligned}
& \int \vec{F}_{I k}=f_{k} \vec{B} \times \vec{I} \mathrm{~d} l=\left\{\vec{F}_{I k x}, \vec{F}_{I k y}, \vec{F}_{I k z}\right\} \mathrm{d} l, \\
& F_{I k}\left(\alpha_{I}+\alpha_{k}, t\right)=f_{k} \mathrm{BI} \sin \theta_{k} \mathrm{~d} l \approx \frac{q}{2|Z|} f_{k} w_{s} L v \Lambda_{0}^{2} \sin \theta_{k} \mathrm{~d} l\left[1+\varsigma \cos \left(-\alpha_{I}-\alpha_{k}-\lambda\right)\right]\left[1+\varsigma \cos \left(-\alpha_{I}-\lambda\right)\right], \\
& \left(\sum_{n=1,3,5 \ldots} \sum_{j=1,3,5 \ldots} k_{w n}\left(F_{r n}-F_{d n}\right) F_{c j}\left[\begin{array}{l}
\cos \left[\frac{(n+j)\left(\omega t-\alpha_{I}\right)-j \alpha_{k}-j \rho_{n}-\psi-\pi}{2}\right] \\
+\cos \frac{(n-j)\left(\omega t-\alpha_{I}\right)-j \alpha_{k}-j \rho_{n}+\psi+\pi}{2}
\end{array}\right]\right. \\
& -\sum_{n=1,3,5 \ldots} \sum_{j=2,4,6 \ldots} k_{w n}\left(F_{r n}-F_{d n}\right) F_{d j}\left[\begin{array}{c}
\cos \left[\frac{(n+j)\left(\omega t-\alpha_{I}\right)-j \alpha_{k}-\psi-\pi}{2}\right] \\
+\cos \left[\frac{(n-j)\left(\omega t-\alpha_{I}\right)-j \alpha_{k}+\psi+\pi}{2}\right]
\end{array}\right] \\
& \left.-\sum_{n=1,3,5 \ldots} \sum_{j=2,4,6 \ldots} k_{w j} F_{d j} F_{c n}\left[\begin{array}{c}
\cos \left[\frac{(n+j)\left(\omega t-\alpha_{I}\right)-j \alpha_{k}-j \rho_{n}-\psi-\pi}{2}\right] \\
+\cos \left[\frac{(n-j)\left(\omega t-\alpha_{I}\right)-j \alpha_{k}-j \rho_{n}+\psi+\pi}{2}\right]
\end{array}\right]\right), \\
& \approx \frac{q}{2|Z|} f_{k} w_{s} k_{w 1} L v \Lambda_{0}^{2} \mathrm{~d} l \sin \theta_{k}\left(F_{r 1}-F_{d 1}\right) F_{c 1}(1+\Delta)\left[\cos \left[\frac{2\left(\omega t-\alpha_{I}\right)-\alpha_{k}-\rho_{n}-\psi-\pi}{2}\right]+\cos \left[\frac{\alpha_{k}+\rho_{n}-\psi-\pi}{2}\right]\right], \\
& \Delta=\varsigma^{2} \cos \left(\alpha_{I}+\alpha_{k}-\lambda\right) \cos \left(\alpha_{I}-\lambda\right)+\varsigma \cos \left(\alpha_{I}+\alpha_{k}-\lambda\right)+\varsigma \cos \left(\alpha_{I}-\lambda\right)
\end{aligned}
$$




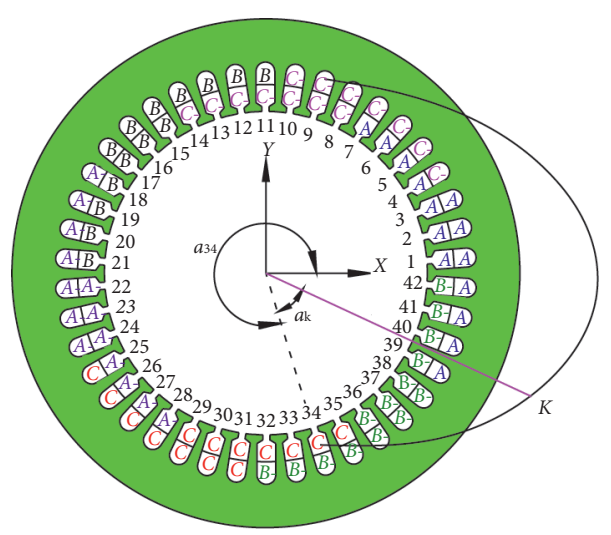

(a)

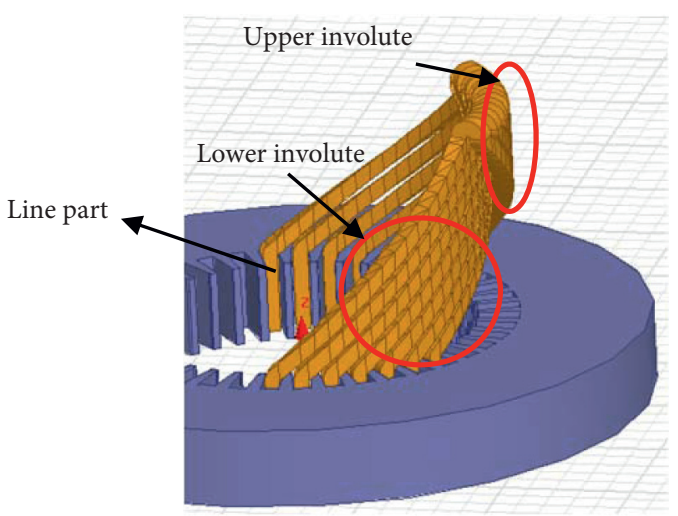

(b)

FIgURE 3: Stator windings: (a) section view and (b) 3D view results and discussion.

where $\theta_{k}$ is the angle between the magnetic flux density and the stator current at point $K ; F_{I k x}, F_{I k y}$, and $F_{I k z}$ are rectangular coordinate components of electromagnetic force. $\alpha_{I}$ is the circumferential angle of the upper layer line part in the $I$-th stator slot, and $\alpha_{I}+\alpha_{k}$ refers to position of the point $K$ as shown in Figure 3(a). The scope of $\alpha_{k}$ is between $0-17 \alpha^{\prime}$, and $\alpha^{\prime}$ refers to the angle between two slots (that is, $8.6^{\circ}$ ).

According to equation (9), the force in composite fault is related not only to rotor and stator MMF, but also to the inverse MMF of RISC (that is, $F_{d}$ ) and the eccentricity factors (that is, $\zeta$ and $\lambda$ ). The harmonics components and $2^{\text {nd }}$ harmonic amplitude in different cases are summed in Table 1 . In addition to the constant and even harmonics, the electromagnetic force in composite fault and RISC also includes odd harmonic components. The amplitude variation of each frequency component depends on $\Delta$ and $F_{d 1}$; that is to say, it is related to the eccentricity angle, eccentricity ratio, short circuit degree, and short circuit position. For coil at the minimum air gap, it exists that $F_{d 1}>0$, $\alpha_{I}+8.5 \alpha^{\prime}=\lambda$ and $\Delta>0$; therefore the second harmonic amplitude of the force decreases under RISC, increases under eccentricity, and is between two single faults after composite fault. While for coil at the max air gap, it exists that $F_{d 1}>0, \alpha_{I}+8.5 \alpha^{\prime}=\lambda+\pi$ and $\Delta<0$, so the second harmonic amplitude of the force decreases after any fault, and the value under composite fault is the smallest.

Moreover, through coordinate transformation and integral calculation, the radial, tangential, axial electromagnetic force components, and resultant force of the end winding under composite fault can be obtained by

$$
\left\{\begin{array}{l}
F_{I r}=\int_{l_{\text {end }}}\left(F_{I k x} \cos \theta+F_{I k y} \sin \theta\right) \mathrm{d} l, \\
F_{I t}=\int_{l_{\text {end }}}\left(-F_{I k x} \sin \theta+F_{I k y} \cos \theta\right) \mathrm{d} l, \\
F_{I a}=\int_{l_{\text {end }}} F_{I k z c} \mathrm{~d} l, \\
F_{I}=\sqrt{\left(\int_{l_{\text {end }}} F_{I k x} \mathrm{~d} l\right)^{2}+\left(\int_{l_{\text {end }}} F_{I k y} \mathrm{~d} l\right)^{2}+\left(\int_{l_{\text {end }}} F_{I k z} \mathrm{~d} l\right)^{2}},
\end{array}\right.
$$

where $\theta$ is the vector angle of the cylinder coordinate of point $K$ and $l_{\text {end }}$ is the coil curve of the end winding.

\section{Simulation}

3.1. Settings. In this section, the electromagnetic force and mechanical response of the end winding in QFSN-6002YHG turbo-generator are calculated by three-dimensional transient finite element method. The study framework is shown in Figure 4. The whole simulation process is carried out on the ANSYS Workbench platform, and the electromagnetic force and mechanical response analysis are realized in the electromagnetic analysis module and structural analysis module, respectively. During the electromagnetic force simulation, the rotor excitation current is set to the rated excitation current $4128 \mathrm{~A}$, the rotor speed is set to the synchronous speed $3000 \mathrm{rpm}$, the time step is $0.0005 \mathrm{~s}$, and 
TABLE 1: Harmonic components and $2^{\text {nd }}$ harmonic amplitude of end winding force.

\begin{tabular}{lcc}
\hline Cases & $2^{\text {nd }}$ harmonic amplitude $\left(C=q / 2|Z| f_{k} w_{s} k_{w 1} L v \Lambda_{0}^{2} d l \sin \theta_{k}\right)$ & Harmonic components $(n+j) \omega,(n-j) \omega$ \\
Normal & $C \cdot F_{r 1} \cdot \sqrt{F_{s 1}^{2} \cos ^{2} \psi+\left(F_{r 1}-F_{s 1} \sin \psi\right)^{2}}$ & $n=1,3,5 \ldots, j=1,3,5 \ldots$ \\
Eccentricity & $C \cdot F_{r 1} \cdot(1+\Delta) \sqrt{F_{s 1}^{2} \cos ^{2} \psi+\left(F_{r 1}-F_{s 1} \sin \psi\right)^{2}}$ & $n=1,3,5 \ldots, j=1,3,5 \ldots$ \\
RISC & $C \cdot\left(F_{r 1}-F_{d 1}\right) \cdot \sqrt{F_{s 1}^{2} \cos ^{2} \psi+\left(F_{r 1}-F_{d 1}-F_{s 1} \sin \psi\right)^{2}}$ & $n=1,3,5 \ldots, j=1,2,3 \ldots$ \\
Composite & $C \cdot\left(F_{r 1}-F_{d 1}\right) \cdot(1+\Delta) \sqrt{F_{s 1}^{2} \cos ^{2} \psi+\left(F_{r 1}-F_{d 1}-F_{s 1} \sin \psi\right)^{2}}$ & $n=1,3,5 \ldots, j=1,2,3 \ldots$ \\
\hline
\end{tabular}

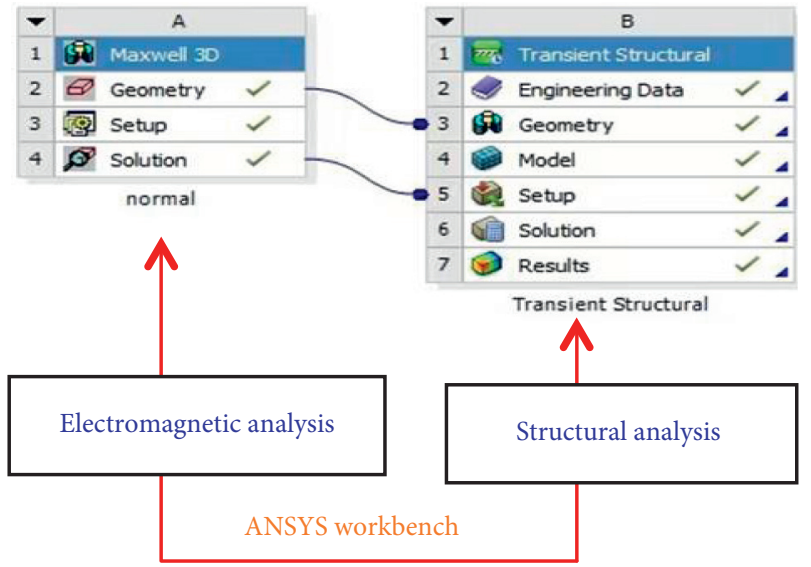

FIgURE 4: Framework of simulation study.

the simulation time is set to $0.12 \mathrm{~s}$. The main parameters, physical model, and grid division of the research object are detailed in $[24,26]$.

The normal air gap is $93 \mathrm{~mm}$, and the eccentricity ratio and angle are set to $30 \%$ and $+X$ axis $\lambda=0^{\circ}$, respectively. The simulation of air gap static eccentricity is realized by moving the stator of the physical model to - $X$ axis by $28 \mathrm{~mm}$. The short circuit degree is set to $5 \%$, and the shorted turn number is 6 . The position of RISC is shown in Figures 2 and $5(\mathrm{a})$, and the center is at $0^{\circ}$. The excitation winding in the short circuit slot is divided into normal turn and shorted turn, which corresponds to the external circuit model, as shown in Figure 5(b).

3.2. MFD Analysis. The normal MFD distribution is shown in Figures 6(a) and 6(b) when $t=100 \mathrm{~ms}$. The MFD is a 3D vector, and it has components in radial, axial, and tangential direction. The synthetical MFD variation wave along tangential and axial direction is shown in Figures 6(c) and 6(d), respectively.

Because eccentricity mainly affects the permeance and RISC will influence the MMF, the MFD will change under the composite fault. It is indicated in Figure 6(c) that, at the min air gap (that is, $0^{\circ}$ or $360^{\circ}$ ), the MFD becomes less under RISC, becomes larger under eccentricity, and is between the two single faults under the composite fault.

The center section of the iron is defined as zero axial coordinate. Therefore, $0-315 \mathrm{~mm}$ is the line part and $315 \sim$ is the end zone. It is shown in Figure 6(d) that the MFD is larger at section of $(0 \sim 600 \mathrm{~mm})$ and decreases rapidly at the section of $(600 \mathrm{~mm})$ whether these faults occurred or not. The section of $(0 \sim 315 \mathrm{~mm})$ is effected by fault greatly, the section of $(315 \sim 600 \mathrm{~mm})$ is little affected, and the section of $(600 \mathrm{~mm})$ ) is least impacted. The reason is that the end leakage field is produced mainly by the stator windings, but the line field is constructed by stator and rotor windings. When the fault happens, both the rotor field and the stator field will change. So the faults affect the line part greatly.

The radial MFD wave and spectrum of point $A$ and point $B$ are shown in Figures $7(\mathrm{a})-7(\mathrm{~d})$. The two points are in the line part and end part of the minimum air gap, respectively, as shown in Figure 6(a).

It indicates in Figures $7(\mathrm{a})$ and $7(\mathrm{~b})$ that the line part MFD contains obvious $50 \mathrm{~Hz}, 150 \mathrm{~Hz}$, and $250 \mathrm{~Hz}$ components and that is fundamental, $3^{\text {rd }}$, and $5^{\text {th }}$ harmonic, respectively. While RISC or composite fault happens, the component of $100 \mathrm{~Hz}$ (that is, $2^{\text {nd }}$ harmonics) increases. In the meantime, the amplitude of $50 \mathrm{~Hz}$ component decreases under RISC, increases under eccentricity, and is between RISC and eccentricity under the composite fault. And these conclusions are consistent with equation (6).

The end part MFD also contains obvious $50 \mathrm{~Hz}$ component as shown in Figures 7(c) and 7(d). It is similar with the line part MFD. At the same time, the amplitude varying of $50 \mathrm{~Hz}$ component is shown in Figures 7(e) and 7(f), and the tendency in the end part is approximate to the line part. This result reflects the reasonability of end part MFD derivation via modifying line part MFD in (9).

\subsection{Electromagnetic Force Analysis on the End Winding.} Because the line part is fixed in the stator slot, the force on this part does not influence the vibration on the end winding. Therefore, we calculated the electromagnetic force on the end involute.

The electromagnetic force distribution of 42 end coils is shown in Figure 8 when $t=100 \mathrm{~ms}$. It is indicated that the electromagnetic force of coils 8-21 under composite fault is less than the value under RISC. This is because these coils are $180^{\circ}$ away from the shorted turn center and the minimum air gap position. So the MMF decreases (see Figure 2(b)), and the permeance also decreases (see Figure 1), resulting in the decrease of MFD and electromagnetic force. On the other hand, the electromagnetic force of coil 29-42 under composite fault is between the two single faults. The reason is that they are just near the shorted turn center and the minimum air gap position. Although the MMF decreases, the permeance increases. 


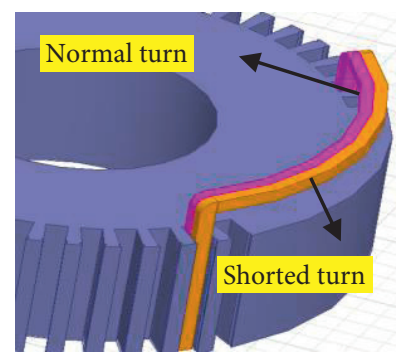

(a)

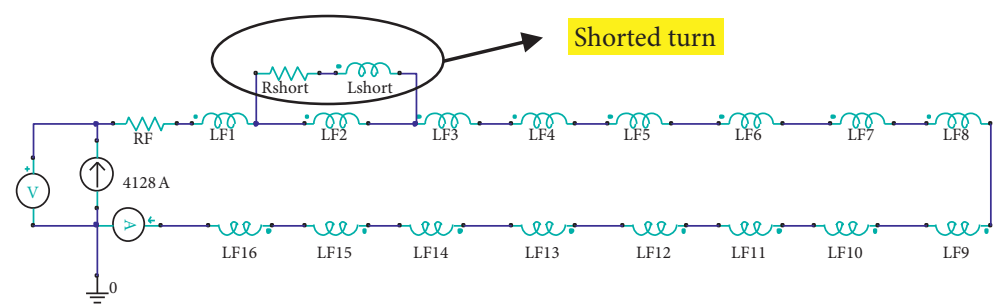

(b)

Figure 5: Setting of RISC: (a) physical model and (b) external circuit model.
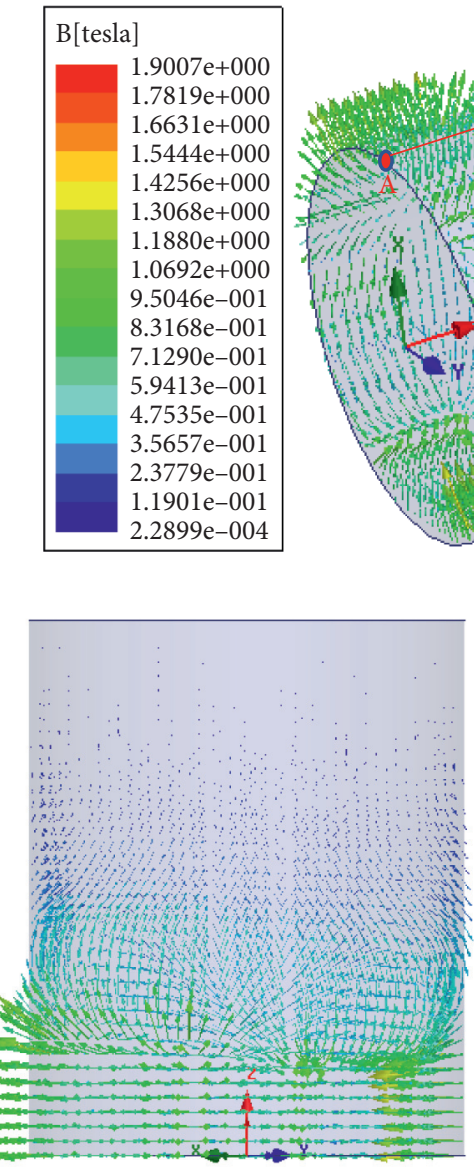

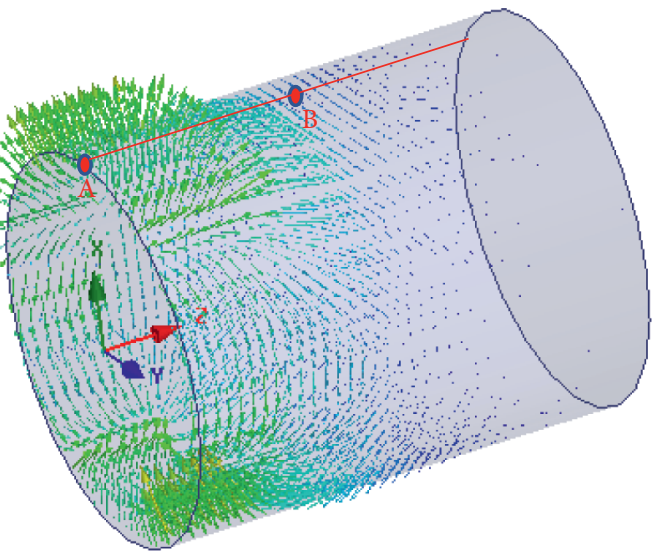

(a)

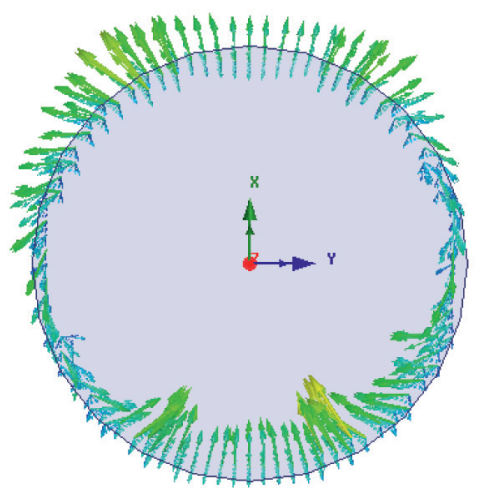

(b)

Figure 6: Continued. 

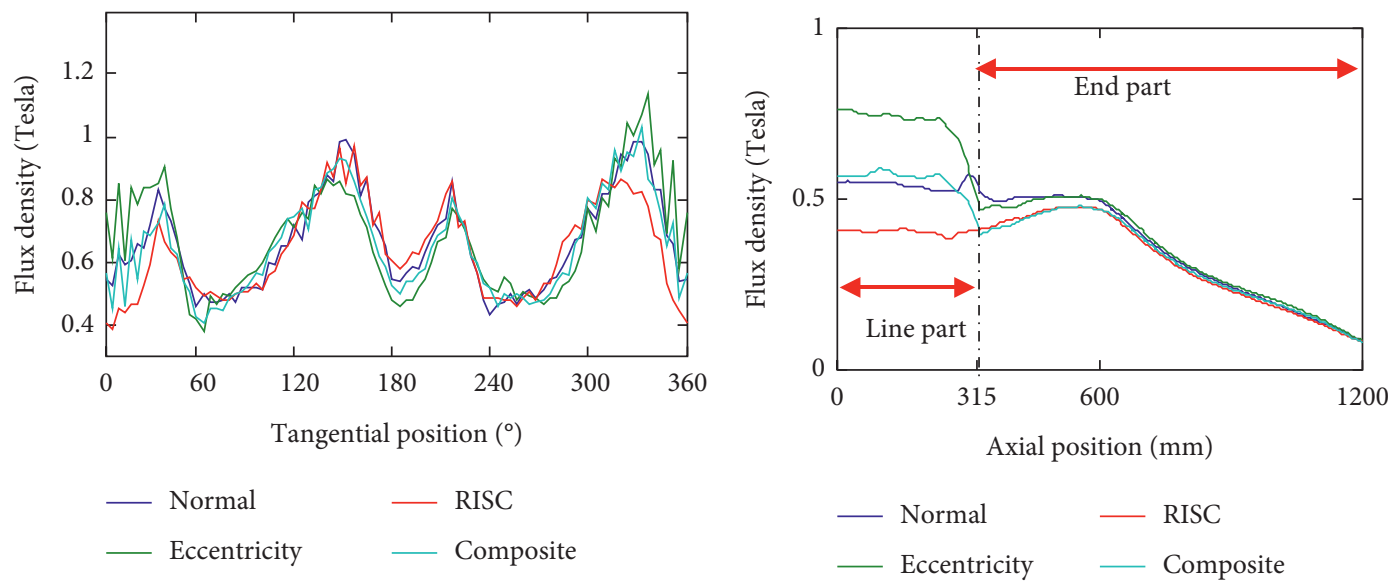

(c)

(d)

FIgure 6: MFD distribution: (a) 3D view, (b) section view, (c) tangential variation wave, and (d) axial variation wave.
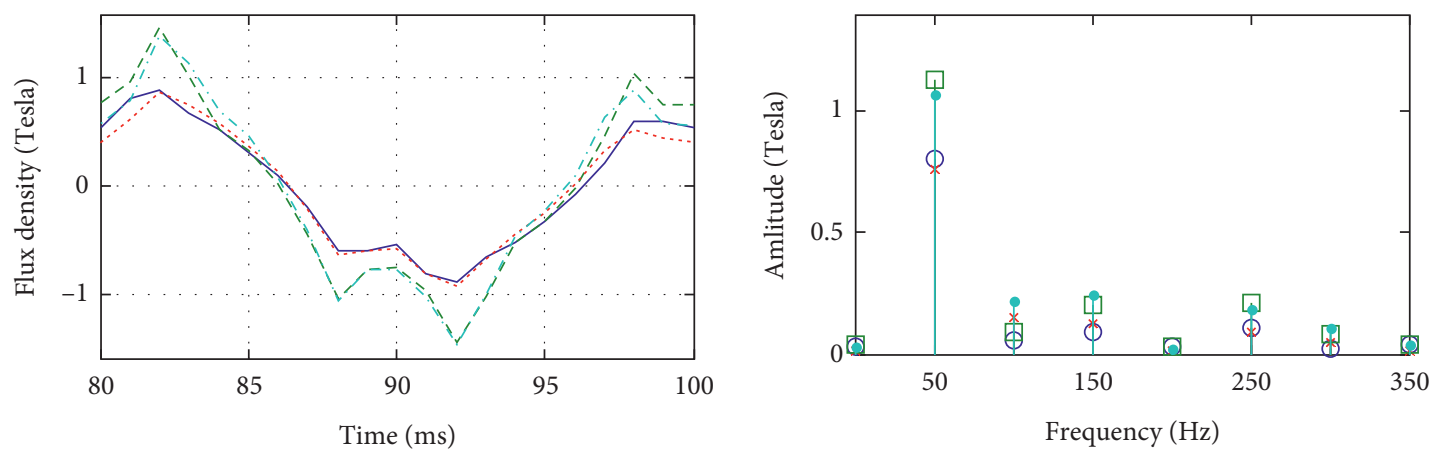

$\begin{array}{lll}\text { _ Normal } & \ldots . & \text { RISC } \\ \text { - - } \text { Eccentricity } & \ldots & \text { Compsite }\end{array}$

(a)

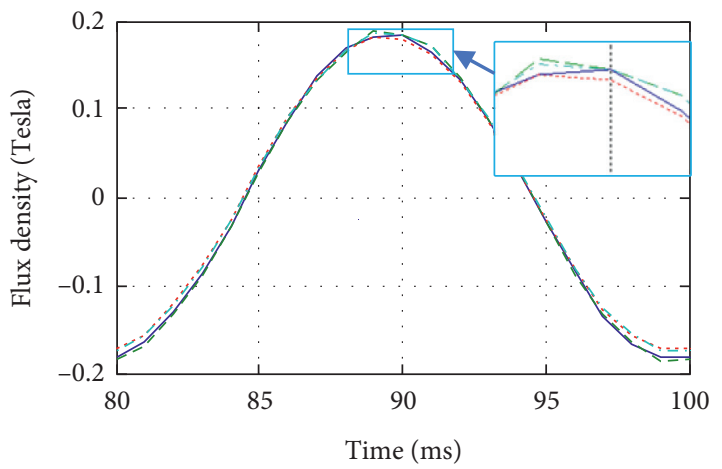

$\begin{array}{lll}\text { - Normal } & \cdots & \text { RISC } \\ --- \text { Eccentricity } & \ldots- & \text { Composite }\end{array}$

(c)

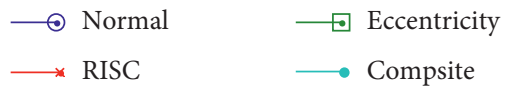

(b)

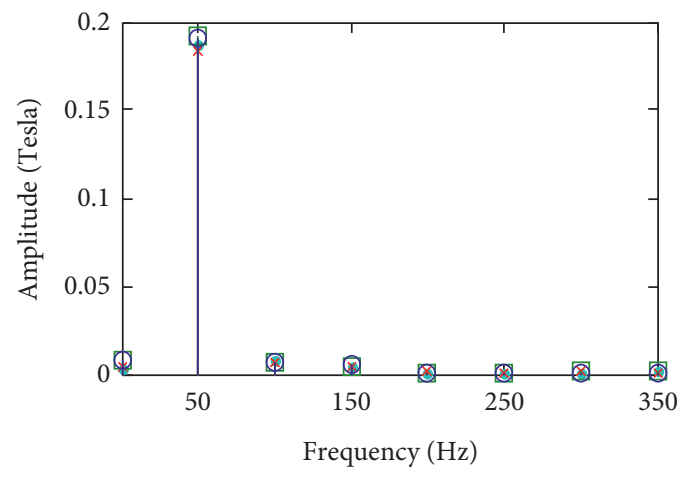

(d)

FIgUre 7: Continued. 


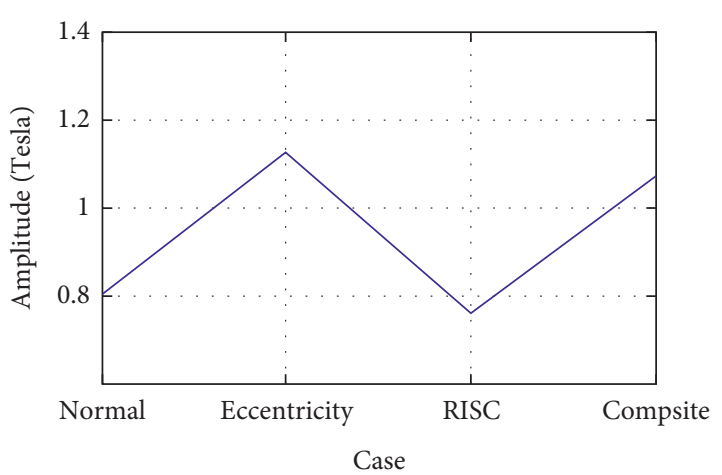

(e)

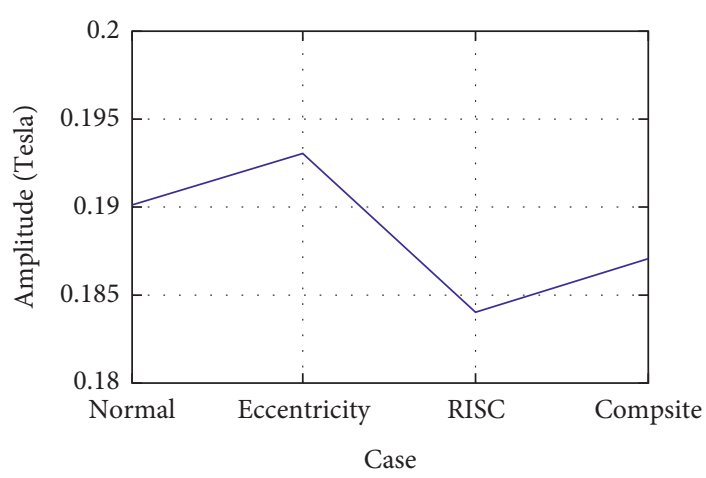

(f)

Figure 7: Radial MFD: (a, b) time wave and spectrum of point A, (c, d) time wave and spectrum of point $\mathrm{B}$, and $(\mathrm{e}, \mathrm{f}) 50 \mathrm{~Hz}$ component amplitude of points $\mathrm{A}$ and $\mathrm{B}$, respectively.

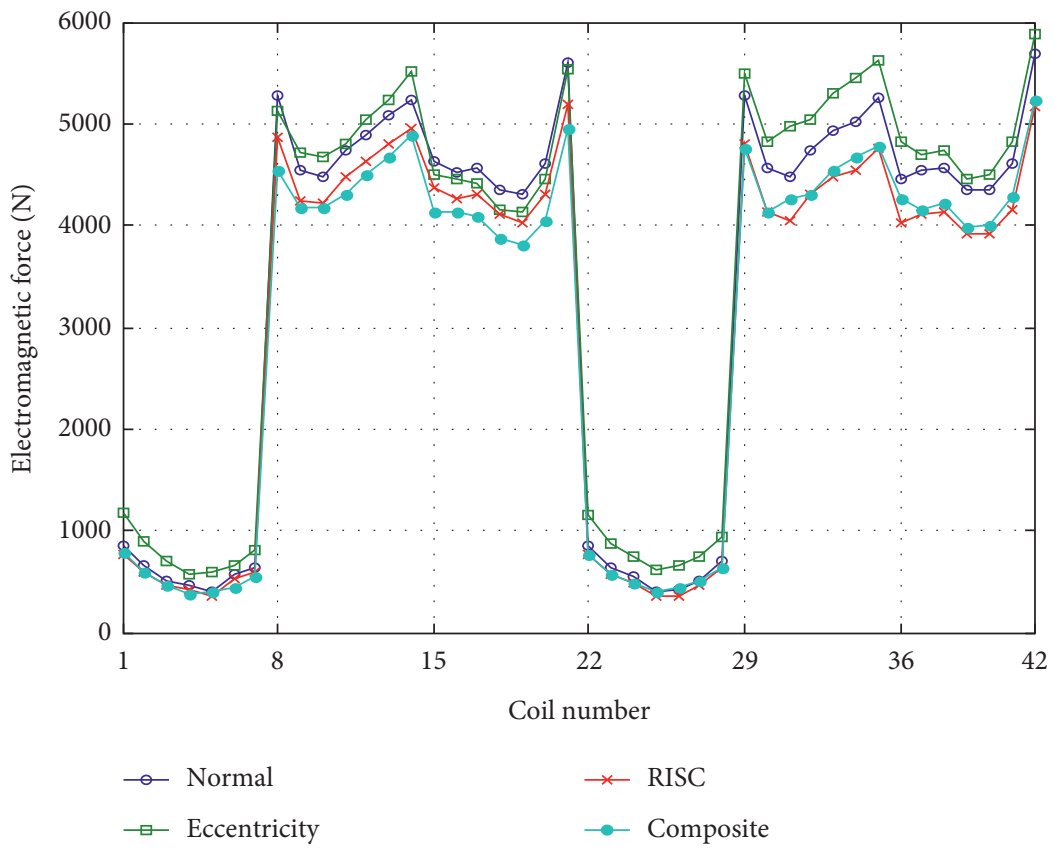

FIGURE 8: End winding electromagnetic force distribution.

The electromagnetic force of coil 34 under composite fault is shown in Figure 9. Figure 9(a) indicates that the force is a three-dimensional vector with components in axial, radial, and circumferential directions. The axial forces of the two involutes both point to the end top, and the radial forces both deviate from the axis. However, the circumferential force of the two parts directs oppositely. As shown in Figure 9(c), in addition to the obvious DC constant, $100 \mathrm{~Hz}$ component, and the weak $200 \mathrm{~Hz}$ component (that is, $4^{\text {th }}$ harmonic), there is a weak component at $150 \mathrm{~Hz}$ (that is, $3^{\text {rd }}$ harmonic), which is consistent with the theoretical analysis result of equation (9).

Since the DC component of the electromagnetic force will not cause the vibration of the winding, and the amplitude of the higher-order component is small, the vibration wearing of the winding is analyzed through the second harmonic component of the force. Because the tangential force directions of the two involutes are opposite, the summed tangential force has little significance for vibration analysis. Therefore, only the $2^{\text {nd }}$ harmonic amplitudes of axial and radial electromagnetic forces before and after the faults are analyzed in Figure 10. Coil 34 is at the min air gap; therefore the electromagnetic force amplitude of the coils near no. 34 increases under eccentricity, decreases under RISC, and is between the two single faults under the composite fault. Different from coil 34, coil 13 is at the max air gap, so the electromagnetic force amplitude of coils near coil 13 decreases under any fault, and it is the smallest in the composite fault.

Affected by the static air gap eccentricity, the force amplitude of coils $60^{\circ}$ apart is no longer equal. For example, during normal operation, the electromagnetic force amplitudes of coils $1,8,15,22,29$, and 36 are approximately equal. Under RISC, the electromagnetic force amplitudes of 


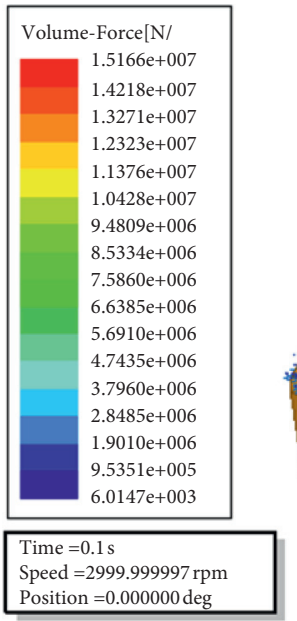

Position $=0.000000 \mathrm{deg}$

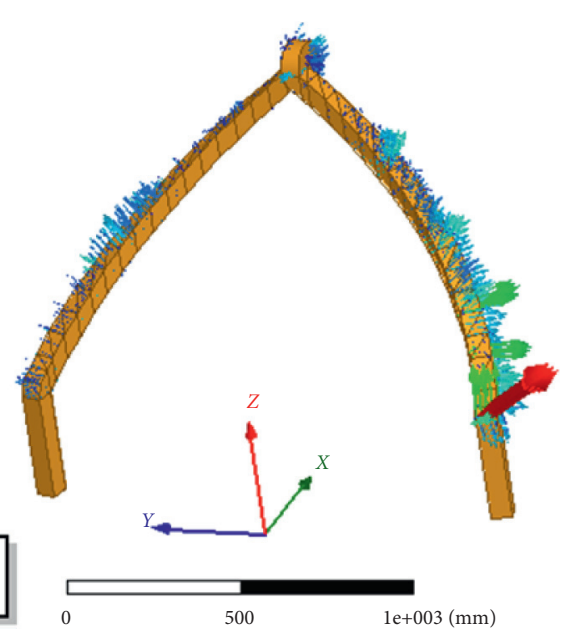

(a)
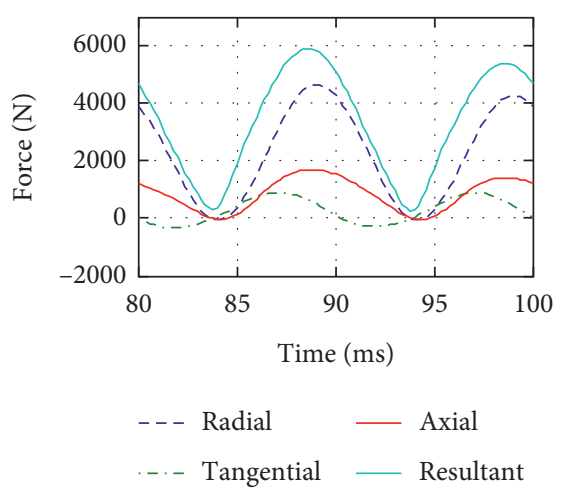

(b)

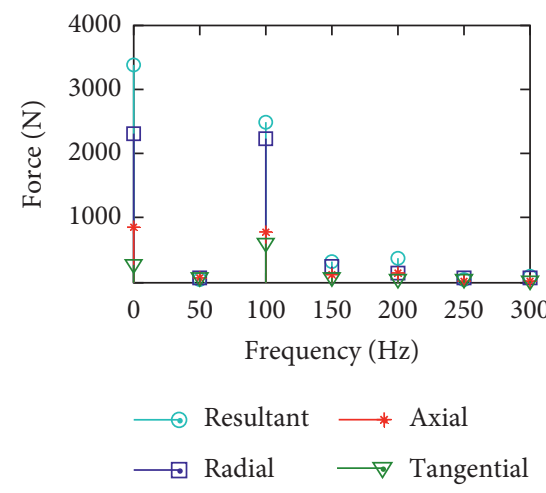

(c)

FigURE 9: Electromagnetic force of coil 34 end part: (a) force density distribution, (b) time wave, and (c) spectrum.

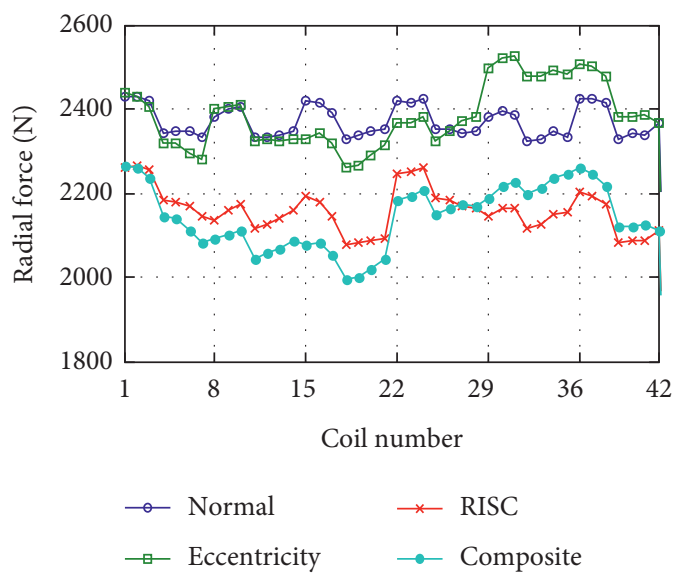

(a)

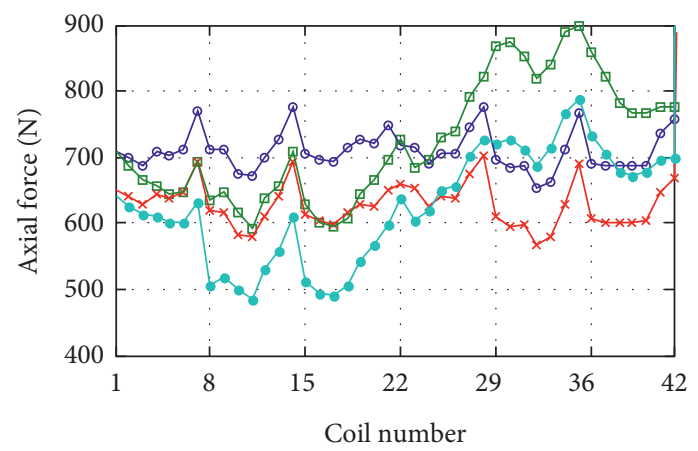

$$
\begin{aligned}
& \rightarrow \text { Normal } \quad \rightarrow \text { RISC } \\
& \rightarrow \text { Eccentricity } \quad \rightarrow \text { Composite }
\end{aligned}
$$

(b)

FIGURE 10: Second harmonic amplitude of electromagnetic force: (a) radial direction and (b) axial direction. 
all coils decrease. Under eccentricity, the electromagnetic force amplitudes of coils 29 and 36 increase, while the electromagnetic force amplitudes of coils 8 and 15 decrease. Under the composite fault, the electromagnetic force amplitude of coils 29 and 36 is between the two single faults, and the electromagnetic force amplitude of coils 8 and 15 is less than any other states.

3.4. Mechanical Response Analysis. The coil is acted by the altering stress and it may be fatigued after many times of cycling repeat. Meanwhile, the wear is induced by friction force and displacement, and the deformation is the presentation of vibration displacement. So we evaluate the wear through deformation in the paper.

The maximum stress and maximum deformation distribution of the windings under the composite fault is shown in Figure 11. Coil 35 is the interphase coil closest to the minimum air gap; it is indicated that the interphase coil closest to the minimum air gap has a high risk of stress fatigue and vibration wear. Therefore, in the process of daily maintenance, we should pay special attention to it.

Moreover, the simulation results show that the maximum stress and deformation occur at the root and nose part, respectively, and the response on the middle part is also larger. So the middle part, the nose part, and the root are the most dangerous zone. This conclusion is consistent with the actual damage as shown in Figure 12.

The maximum stress and deformation of 17 points on coil 34 upper involute are shown in Figure 13. The stress is large at point $Q$ of the involute root, position $\mathrm{H}-\mathrm{I}$ of the middle, and position $\mathrm{A}$ of the nose top, while the deformation at the upper half part of the involute is large. Compared with the normal situation, the maximum stress at the middle, root, and nose changes greatly; the deformation of upper half part varies greatly, while the deformation at the root changes less. The maximum stress and deformation increase under eccentricity, but decrease under RISC. The maximum response value under the composite fault is between the two single faults.

Moreover, the max stress and deformation occurring time on different position are not the same, but they are similar in different cases. Therefore, the key time data of normal condition are summed in Table 2. The max deformation times are mainly on 4 stages, and the max stress times are on 3 stages.

Due to the large deformation of the upper half part, the three-directional deformation amplitudes at position $\mathrm{E}$ of coil 34 are compared in the 4 states, as shown in Figure 14. It is indicated that the radial displacement is the largest in any operation state.

Since the end windings structure two layers (see Figure 3(b)), axial and radial vibration mainly causes wear between adjacent coils in the same layer, as shown in Figure 15(a). The axial and tangential vibration will cause wear between the two neighbouring layers, as shown in Figure 15(b). Because the deformation amplitude in radial is greater than in axial and tangential directions, the wear of windings in the same layer is greater than in the different layers.
Under composite fault, the radial, axial, and circumferential acceleration spectrum at point $\mathrm{E}$ of coil 34 is shown in Figure 16. It indicates that the radial vibration of the end winding is the largest, while the axial vibration and tangential vibration are less. In addition, the vibration components in the three directions contain significant frequency component at $100 \mathrm{~Hz}$ (that is $2^{\text {nd }}$ harmonic). This result is consistent with the simulation result of electromagnetic force, and reflects the frequency corresponding relationship between electromagnetic force and mechanical vibration response.

\section{Experiment Study}

It is pretty hard to test the combined fault data in a practical turbo-generator set, while alternatively the faulty data can be obtained on the simulated prototype generator. The CS-5 fault simulator is particularly designed and manufactured by the authors. Such prototype generator has the same per-unit values as the actual turbo-generator, which means the property variations of the prototype generator can be treated as the representation of the real one. Although the tested data from the prototype generator may have some differences from the practical turbo-generators, the qualitative developing tendency under the faults is consistent with the actual generators.

The CS-5 fault simulation generator set is shown in Figure 17(a)), and it is in Hebei Key Laboratory for health maintenance and failure prevention of electric machinery equipment. The generator has one pair of poles, and the mechanical rotation frequency of the rotor is $50 \mathrm{~Hz}$ as well as the electrical frequency. In the experiment, the acceleration sensor is pasted on the end winding through double-sided adhesive tape, as shown in Figure 17(b)). The vibration of a single winding cannot be measured by the experimental machine, but the measurement results can qualitatively verify the simulation and theory. The exciting current and voltage is set to $1.0 \mathrm{~A}$ and $4 \mathrm{~V}$ respectively, the three-phase load sliding line rheostat is $1000 \Omega$, and the sampling frequency is set to $5000 \mathrm{~Hz}$.

The generator rotor of the unit is fixed on the foundation through bearings, and the stator is placed on the sliding rail that can move along the horizontal radial direction and axial direction. The radial movement of the stator is carried on by adjusting the eccentric setting screw, so as to realize the simulation of the static air gap eccentricity. The eccentricity value is controlled by two dial indicators, as shown in Figure 17(a). During the experiment, the radial eccentricity ratio is set as $30 \%$, and the eccentricity value is $0.36 \mathrm{~mm}$. So the minimum air gap is $0.84 \mathrm{~mm}$ and the maximum air gap is $1.56 \mathrm{~mm}$.

The RISC is simulated by short circuiting the shortcircuit tap on the external wiring board of generator, as shown in Figure $17(\mathrm{c}))$. Three taps are led out at 5\%, 10\%, and $15 \%$ of winding, which can simulate three different RISC degrees. In the experiment, the short circuit degree is set to $5 \%$.

Under composite fault, the three-directional vibration acceleration spectrum of the end winding at the minimum 


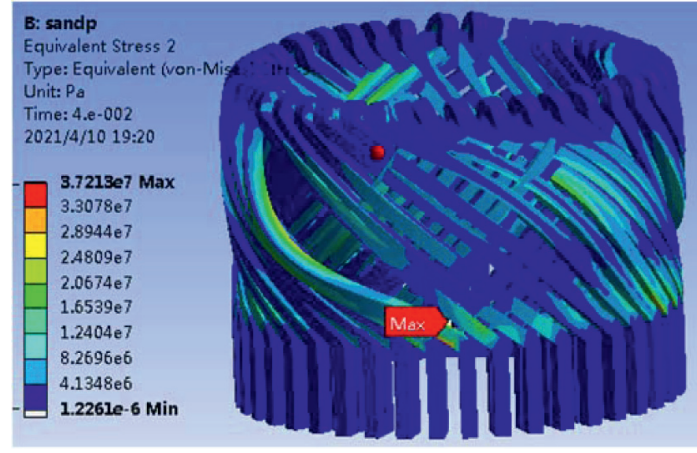

(a)

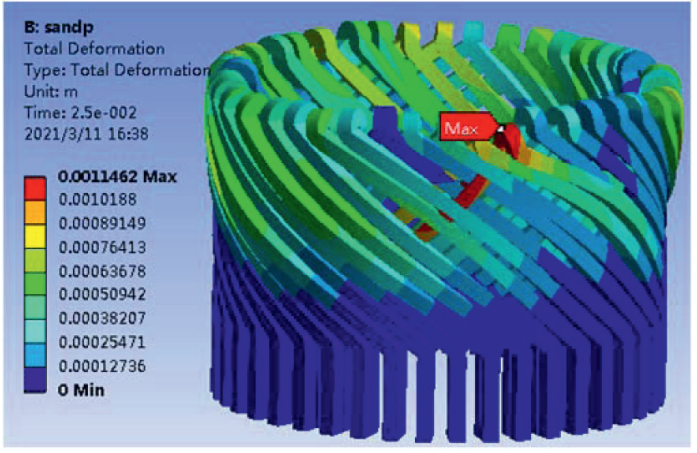

(b)

Figure 11: Max mechanical response of stator windings: (a) max stress and (b) max deformation.

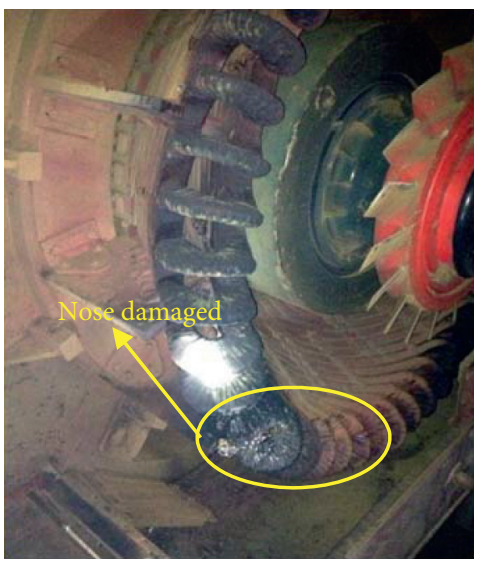

(a)

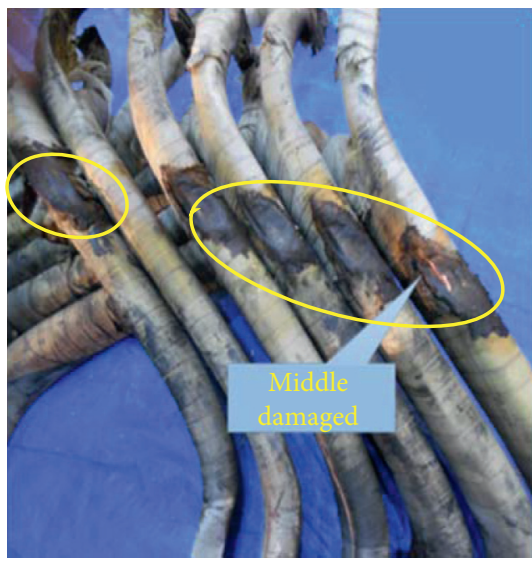

(b)

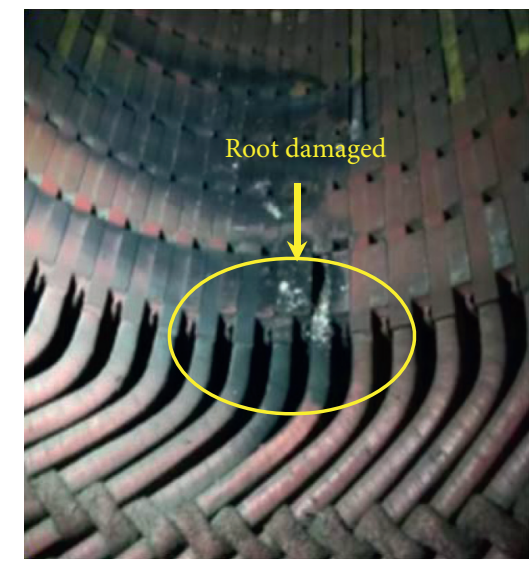

(c)

FIgURE 12: Winding damage in the actual set: (a) nose damage, (b) middle damage, and (c) root damage.

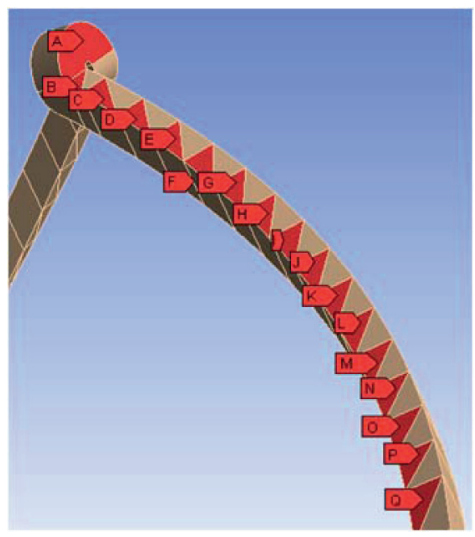

(a)

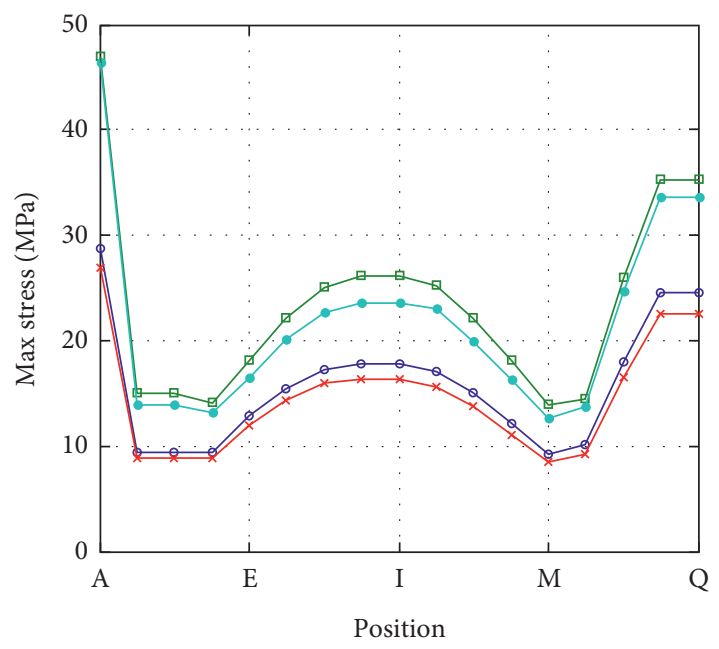

$$
\begin{array}{ll}
\rightarrow \text { Normal } & * \text { RISC } \\
\square \text { Eccentricity } & \rightarrow \text { Composite }
\end{array}
$$

(b)

Figure 13: Continued. 


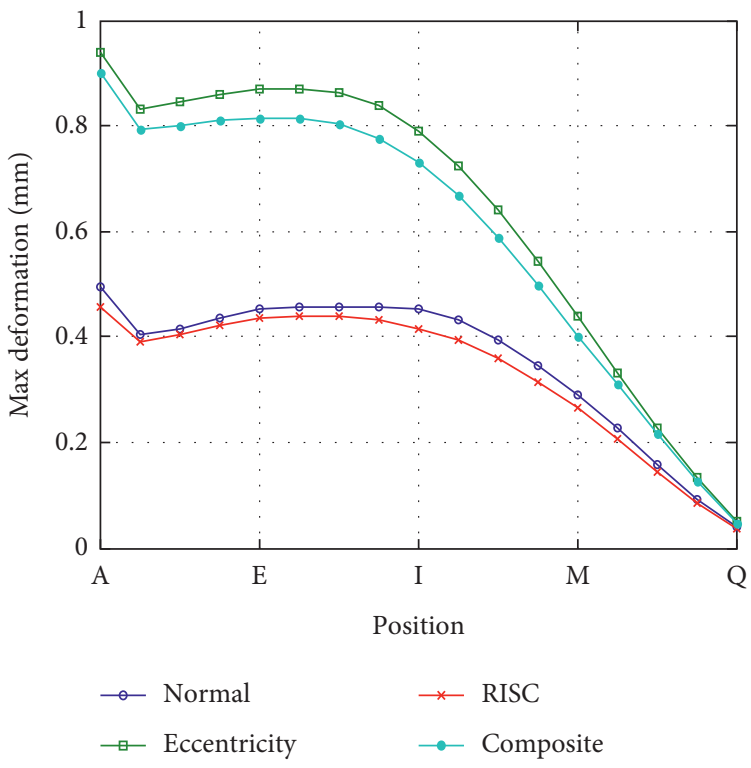

(c)

Figure 13: Max mechanical response distribution on the upper involute of coil 34: (a) probe points, (b) stress distribution curve, and (c) deformation distribution curve.

TABLE 2: Time of max deformation and stress.

\begin{tabular}{lccccccccccccccccc}
\hline Position & $\begin{array}{c}\mathrm{A} \\
(\mathrm{ms})\end{array}$ & $\begin{array}{c}\mathrm{B} \\
(\mathrm{ms})\end{array}$ & $\begin{array}{c}\mathrm{C} \\
(\mathrm{ms})\end{array}$ & $\begin{array}{c}\mathrm{D} \\
(\mathrm{ms})\end{array}$ & $\begin{array}{c}\mathrm{E} \\
(\mathrm{ms})\end{array}$ & $\begin{array}{c}\mathrm{F} \\
(\mathrm{ms})\end{array}$ & $\begin{array}{c}\mathrm{G} \\
(\mathrm{ms})\end{array}$ & $\begin{array}{c}\mathrm{H} \\
(\mathrm{ms})\end{array}$ & $\begin{array}{c}\mathrm{I} \\
(\mathrm{ms})\end{array}$ & $\begin{array}{c}\mathrm{J} \\
(\mathrm{ms})\end{array}$ & $\begin{array}{c}\mathrm{K} \\
(\mathrm{ms})\end{array}$ & $\begin{array}{c}\mathrm{L} \\
(\mathrm{ms})\end{array}$ & $\begin{array}{c}\mathrm{M} \\
(\mathrm{ms})\end{array}$ & $\begin{array}{c}\mathrm{N} \\
(\mathrm{ms})\end{array}$ & $\begin{array}{c}\mathrm{O} \\
(\mathrm{ms})\end{array}$ & $\begin{array}{c}\mathrm{P} \\
(\mathrm{ms})\end{array}$ & $\begin{array}{c}\mathrm{Q} \\
(\mathrm{ms})\end{array}$ \\
\hline $\begin{array}{l}\text { Max } \\
\text { deformation }\end{array}$ & 19 & 19 & 5 & 4.5 & 4.5 & 4.5 & 4.5 & 14.5 & 14.5 & 14.5 & 14.5 & 14.5 & 10 & 10 & 10 & 10 & 10 \\
Max stress & 17 & 17 & 17 & 20 & 19.5 & 19.5 & 19.5 & 19.5 & 19.5 & 19.5 & 19 & 19 & 19 & 10 & 10 & 10 & 10 \\
\hline
\end{tabular}

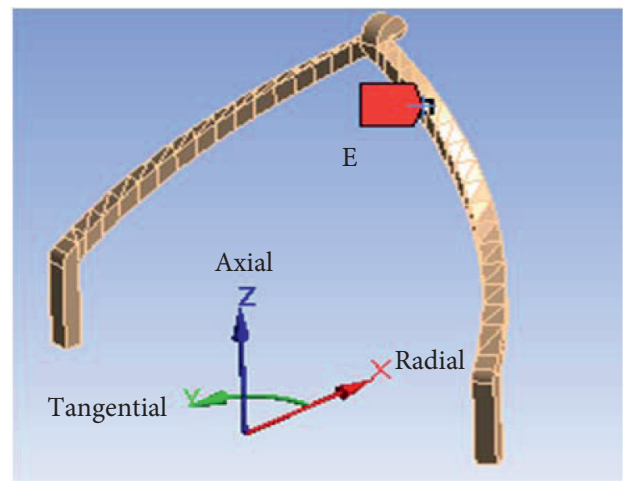

(a)

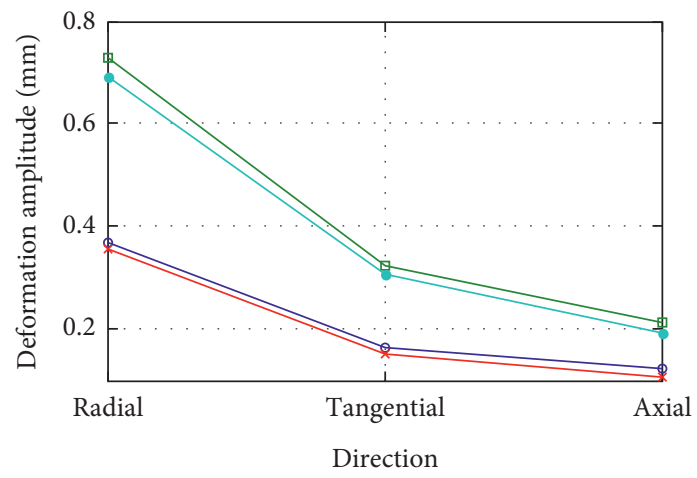

$\begin{array}{ll}\rightarrow \text { Normal } & \rightarrow \text { RISC } \\ \rightarrow \text { Eccentricity } & \rightarrow \text { Composite }\end{array}$

(b)

Figure 14: Max directional deformation: (a) probe point and (b) amplitude.

radial air gap is obtained experimentally, as shown in Figure 18. It is indicated in the figure that the vibration acceleration contains obvious $100 \mathrm{~Hz}$ frequency component (that is, $2^{\text {nd }}$ harmonic). The comparison of $2^{\text {nd }}$ harmonic amplitude before and after fault is shown in Figure 19(a). It shows that the acceleration amplitude increases under 

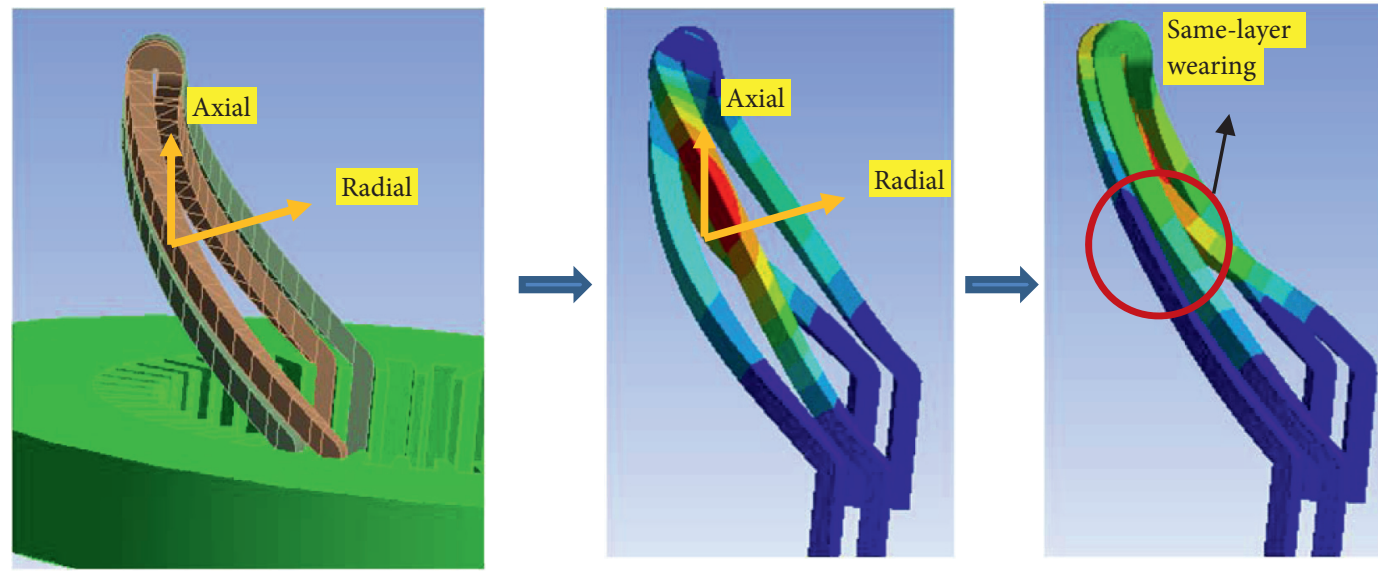

(a)

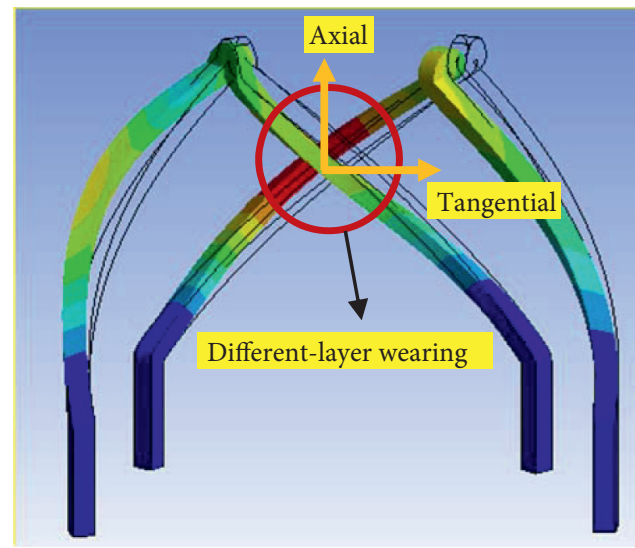

(b)

FIGURE 15: Diagram of coil wearing: (a) the same-layer wearing and (b) different-layer wearing.

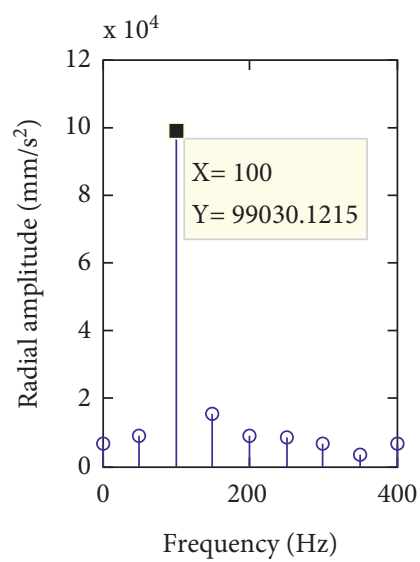

(a)

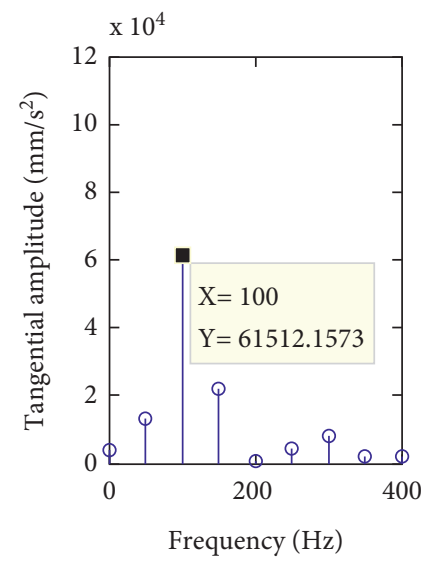

(b)

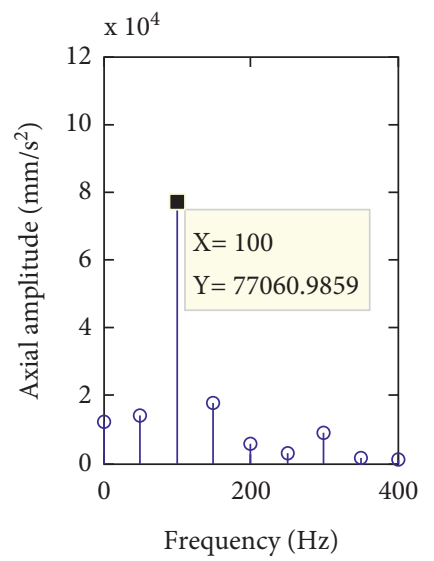

(c)

FIGURE 16: Simulated result of vibration acceleration spectrum: (a) radial direction, (b) tangential direction, and (c) axial direction. 


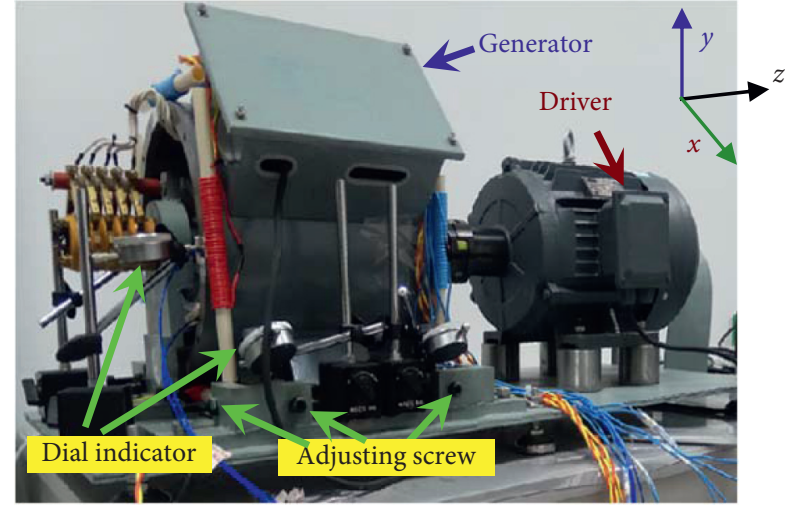

(a)

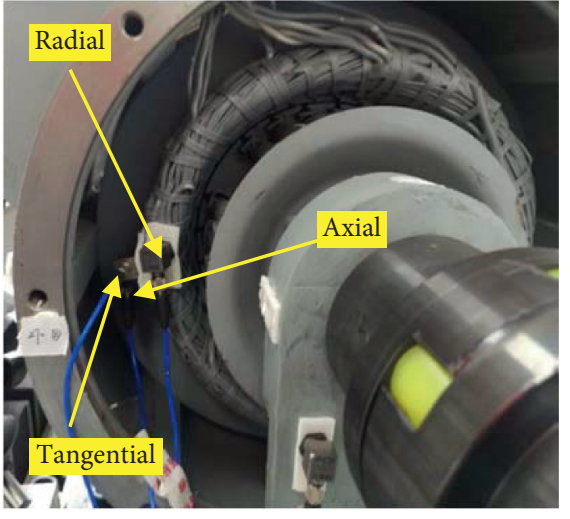

(b)
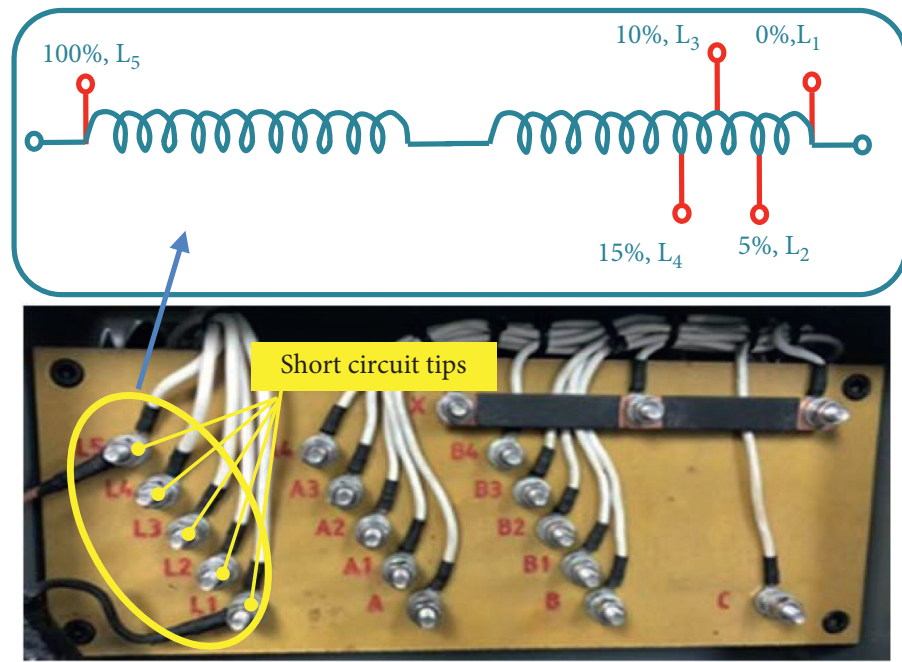

(c)

FIGURE 17: CS-5 fault simulation generator: (a) prototype generator, (b) sensor layout, and (c) short circuit tips.

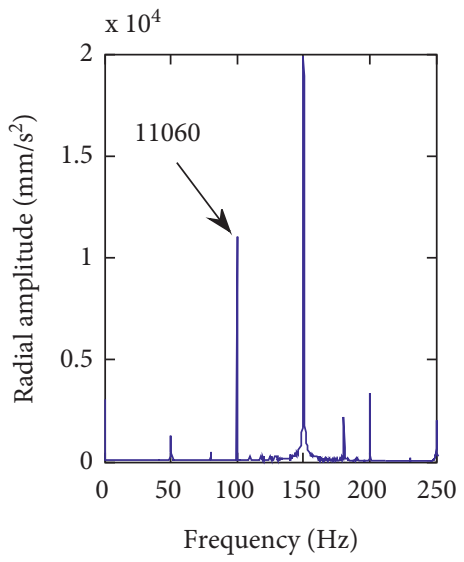

(a)

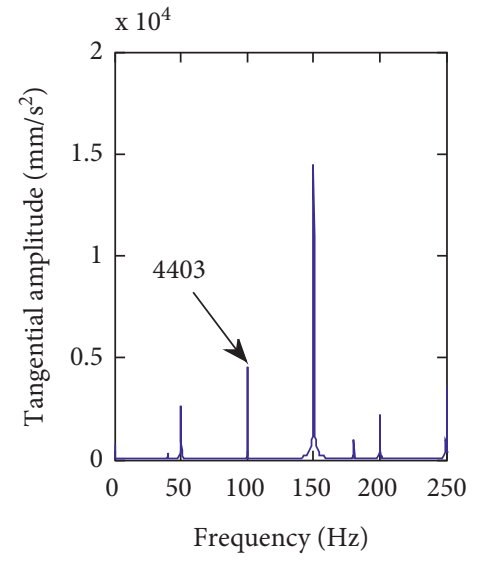

(b)

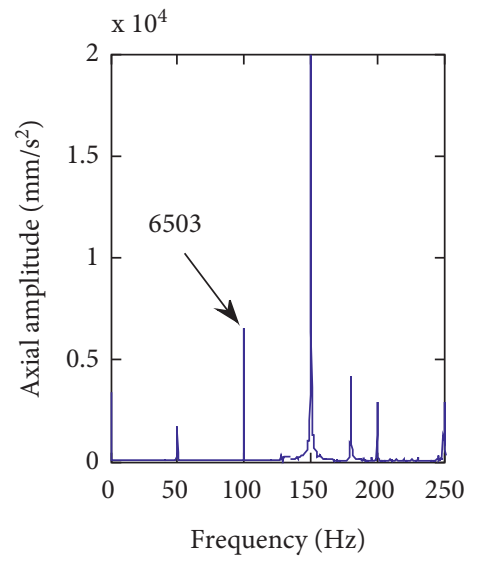

(c)

FiguRe 18: Experimental result of vibration acceleration spectrum: (a) radial direction, (b) tangential direction, and (c) axial direction. 


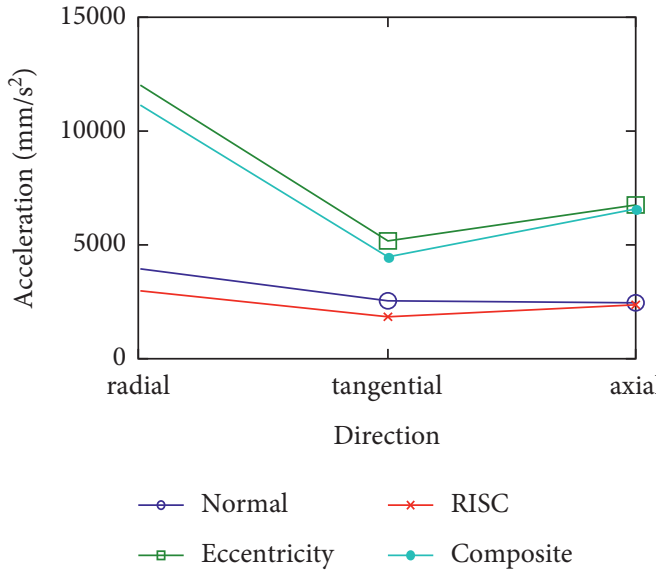

(a)

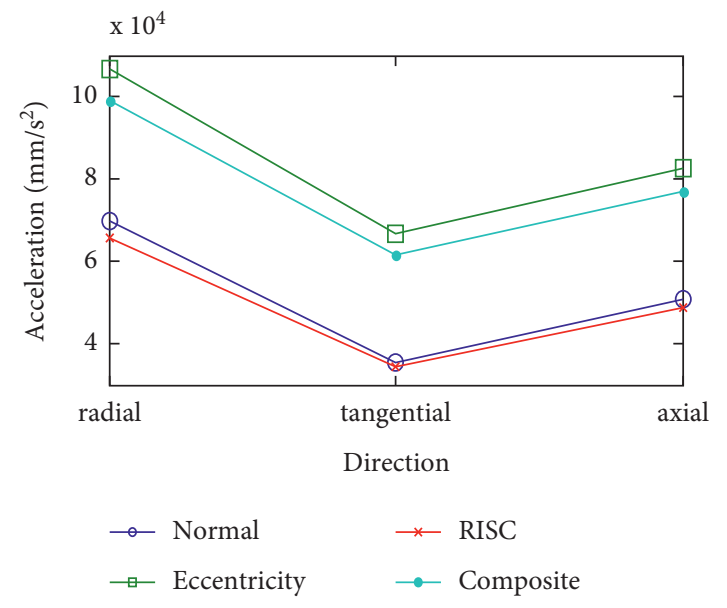

(b)

FIGURE 19: Vibration acceleration comparison: (a) experimental result and (b) simulated result.

TABLE 3: Comparison of vibration characteristics.

\begin{tabular}{|c|c|c|c|c|c|}
\hline \multirow{3}{*}{$\begin{array}{l}\text { Max stress and } \\
\text { deformation }\end{array}$} & & Normal & Eccentricity & RISC & Composite fault \\
\hline & Coil position & Interphase & $\begin{array}{l}\text { Interphase closest } \\
\text { the min air gap }\end{array}$ & Interphase & $\begin{array}{l}\text { Interphase closest } \\
\text { the min air gap }\end{array}$ \\
\hline & $\begin{array}{l}\text { Coil at the min air } \\
\text { gap }\end{array}$ & $\begin{array}{l}S_{n} \\
D_{n}\end{array}$ & $\begin{array}{c}S_{p}>S_{n} \\
D_{p}>D_{n}\end{array}$ & $\begin{aligned} S_{s} & <S_{n} \\
D_{s} & <D_{n}\end{aligned}$ & $\begin{array}{c}S_{s}<S_{c}<S_{p} \\
D_{s}<D_{c}<D_{p}\end{array}$ \\
\hline \multirow{3}{*}{ Vibration } & $\begin{array}{l}\text { Frequency } \\
\text { components }\end{array}$ & $\begin{array}{c}\text { Even } \\
\text { harmonics }\end{array}$ & Even harmonics & $\begin{array}{c}\text { Even and weakly odd } \\
\text { harmonics }\end{array}$ & $\begin{array}{c}\text { Even and weakly odd } \\
\text { harmonics }\end{array}$ \\
\hline & $\begin{array}{c}\text { Amplitude of coils } \\
60^{\circ} \text { apart }\end{array}$ & Equal & Unequal & Equal & Unequal \\
\hline & $\begin{array}{l}2^{\text {nd }} \text { harmonic } \\
\text { amplitude }\end{array}$ & $A_{n}$ & $\begin{array}{l}\text { Min air gap: } A_{p}>\mathrm{A}_{n} \\
\text { Max air gap: } A_{p}<A_{n}\end{array}$ & $A_{s}<A_{n}$ & $\begin{array}{c}\text { Min air gap: } A_{s}<A_{c}<A_{p} \\
\text { Max air gap: } A_{c}<\min \left(A_{s},\right. \\
\left.A_{p}\right)<A_{n}\end{array}$ \\
\hline
\end{tabular}

eccentricity, decreases in RISC, and is between two single faults under composite fault. This result is consistent with the simulation analysis result, as shown in Figure 19(b).

\section{Comparison Analysis of Different States}

Through the analysis of the electromagnetic force and mechanical response, the differences under the normal operation, static eccentricity, RISC, and composite fault are summed in Table 3 , where $D_{n}, D_{p}, D_{s}$, and $D_{c}$ represent the maximum deformation; $S_{n}, S_{p}, S_{s}$, and $S_{c}$ represent the maximum stress; $A_{n}, A_{p}, A_{s}$, and $A_{c}$ represent the $2^{\text {nd }}$ harmonic amplitude of vibration acceleration under the four states, respectively.

(1) Position of maximum stress and maximum deformation: during normal operation and RISC, the maximum stress and deformation occur on the interphase coil. In case of eccentricity and composite faults, the maximum stress and deformation occur on the interphase coil closest to the minimum air gap.

(2) Maximum stress and deformation of coil at the minimum air gap: the maximum stress and deformation of the end coil at the minimum air gap become larger under eccentricity than in normal operation, but they become less under RISC. And the maximum values under composite fault are between two single faults.

(3) Frequency component of vibration: during normal operation and static eccentricity, the vibration of end winding contains even harmonics, and in case of RISC and composite fault, weak odd harmonics will appear in the spectrum.

(4) Vibration amplitude of coils $60^{\circ}$ the vibration amplitude of end winding separated by $60^{\circ}$ is approximately equal in normal operation and RISC. While in the case of static eccentricity and composite fault, the vibration amplitudes are different.

(5) 2nd harmonic amplitude of vibration acceleration: for the coil at the minimum air gap, the amplitude of the second harmonic amplitude of vibration acceleration will increase when the static eccentricity occurs, but will decrease under RISC. And under the composite fault, the amplitude will be between the two single faults. For the coil at the maximum air gap, the 2nd harmonic amplitudes of vibration acceleration will decrease in the case of faults and its amplitude is the smallest under the composite fault. 


\section{Conclusions}

In this paper, the electromagnetic force and mechanical response of turbo-generator stator end winding before and after typical electromechanical faults are theoretically analyzed, simulated with finite element method, and verified by experiments. It is found that, under the composite fault, weakly odd harmonic component will be brought. Meanwhile, the second harmonic amplitudes of the three-directional vibrations are between two single faults for the coil at the minimum air gap, and it is smallest in the four states for coil at the maximum air gap. Moreover, the maximum stress and deformation under composite fault occur on the interphase coil closest to the minimum air gap. Under any operating conditions, the same-layer wear is greater than the different-layer wear. The fault mainly affects the fatigue strength of the nose, middle, and root part and chiefly affects the vibration wear of the upper half part for the involute, and the influence trend is the same as the second harmonic amplitude of the vibration.

This paper is an exploration of the research method, and the analysis results have a certain reference value for the actual situation. In the future study, the fixed mode of windings can be considered for more accurate simulation and analysis.

\section{Data Availability}

The data used to support the findings of this study are available from the corresponding author upon request.

\section{Conflicts of Interest}

All authors declare that there are no conflicts of interest regarding the publication of this study.

\section{Acknowledgments}

This work was supported by the National Natural Science Foundation of China (51777074) and the Fundamental Research Funds for Central Universities (2017MS146).

\section{References}

[1] J. Tegopoulos, "Forces on the end winding of turbine-generators I - determination of flux densities," IEEE Transactions on Power Apparatus and Systems, vol. 85, no. 2, pp. 105-113, 1966.

[2] J. A. Tegopoulos, "Forces on the end winding of turbinegenerators II - determination of forces," IEEE Transactions on Power Apparatus and Systems, vol. 85, no. 2, pp. 114-122, 1966.

[3] Y. Wu and Y. Li, "Experimental study of rotor inter-turn short circuit fault diagnosis in turbine generator based on characteristic frequency of end-leakage-flux," Transactions of China Electro-Technical Society, vol. 11, pp. 107-115, 2014, in Chinese.

[4] Y. Sun, X. Yu, W. Kun, and Z. Huang, "A new type of search coil for detecting inter-turn faults in synchronous machines," Proceedings of the CSEE, vol. 6, pp. 917-924, 2014, in Chinese.
[5] W. Yucai and L. Yonggang, "Diagnosis of rotor winding interturn short-circuit in turbine generators using virtual power," IEEE Transactions on Energy Conversion, vol. 30, no. 1, pp. 183-188, 2015.

[6] L. G. Yong, Z. J. Yan, L. Chen, and X. Ji, "Fault diagnosis of rotor winding inter-turn short circuit in turbine-generator based on BP neural network," in Proceedings of the 2008 International Conference on Electrical Machines and Systems, pp. 783-787, Wuhan, China, October 2008.

[7] W. Yucai, M. Qianqian, and C. Bochong, "Fault diagnosis of rotor winding inter-turn short circuit for sensorless synchronous generator through screw," IET Electric Power Applications, vol. 11, no. 8, pp. 1475-1482, 2017.

[8] S. Wan, Y. Li, H. Li, and G. Tang, "The new diagnosis method of rotor winding inter-turn short circuit fault and imbalance fault based on stator and rotor vibration characteristics," in Proceedings of the 2005 International Conference on Electrical Machines and Systems, vol. 3, pp. 2207-2210, Nanjing, China, September 2005.

[9] W. Shuting, L. Yonggang, L. Heming, and T. Guiji, “A compositive diagnosis method on turbine-generator rotor winding inter-turn short circuit fault," in Proceedings of the 2006 IEEE International Symposium on Industrial Electronics, pp. 1662-1666, Montreal, QC, Canada, July 2006.

[10] B. A. T. Iamamura, Y. l. Menach, A. Tounzi, N. Sadowski, and E. Guillot, "Study of static and dynamic eccentricities of a synchronous generator using 3-D FEM," IEEE Transactions on Magnetics, vol. 46, no. 8, pp. 3516-3519, 2010.

[11] G. Zhang, W. Junchao, H. Huang, and M. Zhou, "A study on the nonlinear vibration of the generator rotor based on the unbalanced electromagnetic force and the oil film force coupling model," Journal of Vibroengineering, vol. 15, no. 1, pp. 23-36, 2013.

[12] C. Patsios, A. Chaniotis, E. Tsampouris, and A. Kladas, "Particular electromagnetic field computation for permanent magnet generator wind turbine analysis," IEEE Transactions on Magnetics, vol. 46, no. 8, pp. 2751-2754, 2010.

[13] Y. L. He, M. X. Xu, J. Xiong et al., "Effect of 3D unidirectional and hybrid SAGE on electromagnetic torque fluctuation characteristics in synchronous generator," IEEE Access, vol. 7, Article ID 100823, 2019.

[14] Y. L. He, Y. X. Sun, M. X. Xu et al., "Rotor UMP characteristics and vibration properties in synchronous generator due to $3 \mathrm{D}$ static air-gap eccentricity faults," IET Electric Power Applications, vol. 14, no. 6, pp. 961-971, 2020.

[15] H. Ehya, I. Sadeghi, and J. Faiz, "Online condition monitoring of large synchronous generator under eccentricity fault," in Proceedings of the 2017 12th IEEE Conference on Industrial Electronics and Applications (ICIEA), pp. 19-24, Siem Reap, Cambodia, June 2017.

[16] Y. He, Electromechanical Characteristics Analysis of Generator under Composite Fault of Air gap Eccentricity and Winding Inter Turn Short Circuit," Baoding, China:North china electric power university, Beijing, China, 2012, in Chinese.

[17] S. Wang, Y. Zhang, and Y. Hu, "Analysis of impact of rotor winding inter-turn short circuit faults on electromagnetic torque," Electric Machines and Control, vol. 16, no. 8, pp. 17-22+28, 2012, in Chinese.

[18] Y. He, Z. J. Zhang, and W. Q. Tao, W. L. Xiao, D. Gerada, C. Gerada, and P. Gao, A New External Search Coil Based Method to Detect Detailed Static Air-Gap Eccentricity Position in Non-salient Pole Synchronous Generators," IEEE Transactions on Industrial Electronics, vol. 68, no. 8, 2020. 
[19] M. Valavi, K. G. Jorstad, and A. Nysveen, "Electromagnetic analysis and electrical signature-based detection of rotor inter-turn faults in salient-Pole synchronous machine," IEEE Transactions on Magnetics, vol. 54, no. 9, pp. 1-9, 2018.

[20] J. Yun, S. Park, C. Yang et al., "Comprehensive monitoring of field winding short circuits for salient Pole synchronous motors," IEEE Transactions on Energy Conversion, vol. 34, no. 3, pp. 1686-1694, 2019.

[21] Y. Li, Y. Sun, L. Wang, and Hai, "The criterion on inter-turn short circuit fault diagnose of steam turbine generator rotor windings," in Proceedings of the 2007 International Conference on Electrical Machines and Systems (ICEMS), pp. 1050-1054, Seoul, Korea (South), October2007.

[22] Y. He, D. Gerada, X. X. Ming et al., "Impact of stator interturn short circuit position on end winding vibration in synchronous generators," IEEE Transactions on Energy Conversion, vol. 36, no. 2, 2020.

[23] Q. Meng and Y. He, "Mechanical response before and after rotor inter-turn short-circuit fault on stator windings in synchronous generator," in Proceedings of the 2018 IEEE Student Conference on Electric Machines and Systems, pp. 1-7, HuZhou, China, December 2018.

[24] H. C. Jiang, G. J. Tang, Y. L. He, K. Sun, W. J. Li, and L. Cheng, "Effect of static rotor eccentricity on end winding forces and vibration wearing," International Journal of Rotating Machinery, vol. 2021, Article ID 5554914, 14 pages, 2021.

[25] G. J. Tang, H. C. Jiang, Y. L. He, and Q. F. Meng, "Electromagnetic forces and mechanical responses of stator windings before and after rotor interturn short circuit in synchronous generators," Mathematical Problems in Engineering, vol. 2020, Article ID 5892312, 19 pages, 2020.

[26] H.-C. Jiang, Y. L. He, G. J. Tang, and X. X. Ming, “A comprehensive analysis on transient electromagnetic force behavior of stator windings in turbo-generator," Mathematical Problems in Engineering, vol. 2018, Article ID 4189609, 16 pages, 2018. 